\title{
The Effectiveness of Teaching Reading Skill Using Communicative Approach in Malaysian Secondary Homeschooling ESL Classroom
}

Hon Kai Lai (Kellie)

School of Education, Taylor University, Selangor, Malaysia

Corresponding Author: Hon Kai Lai (Kellie), E-mail: kellyhon711@gmail.com

\section{ARTICLE INFORMATION}

Received: November 17, 2021

Accepted: January 04, 2021

Volume: 4

Issue: 1

DOI: 10.32996/ijllt.2021.4.1.14

\section{KEYWORDS}

Communicative language teaching, homeschooling, ESL, reading comprehension

\section{ABSTRACT}

The objectives of this study are to investigate the perceptions of the secondary homeschooling students on the use of the communicative approach (CLT) in their reading classrooms and to find out to what extent CLT contributes to the development of ESL learners' reading skill. Four procedures were employed for data collection which included Pre-test and Post-Test, Classroom Observation, Questionnaire and Structured Interview. In general, the results in the Experimental Group showed that there was significant improvement among the learners between pre and post-test scores. Therefore, we can conclude that there was a significant improvement in scores between pre-test to post-test scores. Most secondary homeschooling students are enthusiastic and positive about the communicative approach in their ESL reading classrooms, whereby they learn more vocabulary through group discussions and improve their reading comprehension when exchanging ideas and opinions. Responses and attitude were very positive and strongly agreed with the use of CLT for improving their reading skills as the CLT approach has changed the reading class atmosphere to be better than before. Therefore, the homeschooling students felt pretty cheerful, comfortable and excited during the learning process of reading using CLT activities. Besides that, both homeschooling teachers tend to have a clear, positive and supportive attitudes and perceptions toward CLT. They strongly agreed that CLT is an effective and useful teaching method to accommodate the demands of the time as this method put high emphasis on the interpersonal skill, stimulate the students to communicate their enthusiasm as well as stimulate their interest in their language learning process. Moreover, this approach is advantageous and favourable as the approach is to involve every student in the communicative activities and places high emphasis on communication which highly encouraged the students to communicate and interact with each other as well as stimulate their interest in English learning and developing their learner autonomy.

\section{Introduction}

In today's global world, it cannot be denied that English plays a crucial role in communication since it is the most accepted language spoken in many different places worldwide. With advances in technology, English has a dominant role in various sectors including engineering, medicine and education, which are three of the most crucial fields where English is highly essential. Specifically, a developing country like Malaysia has to accept and apply this world-wide spoken language in all sectors in order to confirm its international status (Kunzman \&amp; Gaither, 2013).

There is an increasing recognition and extensive acceptance of Communicative Language Teaching (CLT) as an effective approach in language teaching and learning in many Asian countries including Malaysia. This effective method has a meaningful effect on how language is mastered and taught. In reality, late 1970s saw Malaysia accepting CLT in English as a Second

K C AL-KINDI CENTER R D FOR RESEARCH AND DEVELOPMENT Your gateway to world-class research

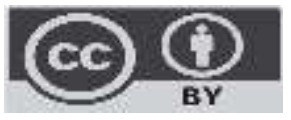

Published by Al-Kindi Center for Research and Development. Copyright (c) the author(s). This open access article is distributed under a Creative Commons Attribution (CC-BY) 4.0 license 
Language (ESL) teaching, somewhat taking the place of the structural-situational syllabus of English when the communicative syllabus was completely implemented in upper secondary schools in 1977 (Chan \&amp; Tan, 2006).

CLT refers to both processes and objectives in classroom learning with an attempt to practice the communicative competence concept (Richards, 2001). CLT emphasizes communication as both the means and the ultimate aim of learning a language. The teaching and learning of ESL in Selangor home-schools adopts CLT and aims to get learners engaged in real-life communication in the English language. Classroom enrollment in home-schools, which is around 20 learners per class should enable English language teachers assist individual learners to participate in the learning process. The small class size allows for personalised teacher attention and active learner participation in every home-school class which are normally between 40 and 80 minutes per session. The main objective of CLT approach is for meaningful communication through activities designed for learning. Since the process of teaching and learning is mutual, students play a major role in learning the target language. Commonly, this approach is acknowledged as a new means to language instruction which has evolved in response to the comprehension that "knowledge of grammatical forms and structures alone does not sufficiently develop the learners effective and proper application of the language they are acquiring" (Celce, 2009, pg 66). Furthermore, this approach is established on the hypothesis that language is a vehicle of communication and thus the major purpose of learning a language is being able to communicate appropriately and efficiently.

The implementation of CLT has encountered difficulties and opposition in the Malaysian ESL reading classroom (Kasim, 2015). According to the Motteram (2013), the delivery of language instruction is still based on conventional methods normally observed in the ESL reading classrooms. This is due to the many different new CLT ideas compared to the instructional value and traditions of many ESL reading settings (Henrichsen, 2007). Furthermore, circumstantial factors such as the exam-oriented approach already rooted in the Malaysian education system and the low English language competency among home-school students seem to have significant implications on the practices and implementation of CLT in the Malaysian secondary English reading Classes. Therefore, in order to ensure successful implementation of CLT in the Malaysian secondary English reading classes, an understanding of the secondary home-school students' opinions regarding CLT applications in their reading classrooms should be clarified. This could be new information It is essential and crucial to have an understanding of the secondary home-schools students' opinions regarding the application of CLT in English reading classrooms so that educational stakeholders, especially our Ministry of Education can carefully examine significant factors surrounding the implementation of CLT in our secondary English reading classes in order to enhance English proficiency among Malaysian home-schools students.

\subsection{Background of the study}

In Malaysia, English is the major second language for many sectors of the economy including education, businesses, medical, engineering, law, as well as travelling abroad. English is taught as a compulsory subject from primary one to secondary five in all homeschools in Malaysia. The conventionally applied Grammar Translation Method (GTM) is unable to yield positive outcomes, as the more extensive knowledge spheres, world globalization and the comprehensive application of English language in all domains of life requires the future generation to become specialists in the application of the English language, not only in its written form but also in its verbal communication. It is applied as a tool and means toward significant objectives (Chang, 2011). In Malaysia, English should be taught from an applied linguistics point of view (Motteram, 2013). In other words, whatever the home-school students learn in the classroom should be closely related to their real life situations.

Generally, English is regarded as a second language in Malaysian homeschooling. The advocates of ESL declare that although English is the language of business, military affairs, education and others, it is not a communication vehicle among the public. As a result, the majority of secondary home-school students hardly find any opportunity to apply English outside the home-school classroom (Kunzman \&amp; Gaither, 2013). Thus, English has a second language context in Malaysian homeschooling.

Reading is an essential skill for students in ESL context and reading comprehension is an interactive and complicated process affected by linguistic and cognitive factors, social and cultural factors and affective and motivational factors (Yu, 2001). As pointed out by Ying (2010), powerful reading skills enable ESL learners to build more development and acquire huge growth in all academic domains. Despite the attention given to reading by teachers and students in Malaysia and the claim that reading as a skill is built up through the CLT approach, the development of reading instruction and the reading abilities of the students are unacceptable in the Malaysia ESL context. Most probably, the occurrence of this incident is due to lack of linguistic input among the ESL students, disconcerting school culture and learning environment, as well as provision of improper reading materials.

Society at large, especially parents need to be more aggressive in educating and cultivating good reading habits among the children from a young age. Reading starts at home and parents are the main indicators of whether their child is achieving the 
learning habit. Children at a delicate age are more like sponges giving nourishment to their minds knowledge and useful information from their parents who act as their role model. In order to provide a powerful platform for the children to develop a strong passion in reading, the children should be equipped with definite and good reading habits at a young age. Since school teachers are heavily engaged with their routine stressful work of cultivating and teaching children, parents should therefore play a crucial role in developing and cultivating their children to spend more time reading as this will improve the social bondage between them (Inderjit, 2014). Assuming that our youth can spend their extra time reading and developing critical thinking,social problems such as drug-taking, illegal racing, baby-dumping and so on will be reduced in our society.

\subsection{Problem Statement}

According to Chan and Tan (2006), there are many unemployed fresh local graduates who are experiencing obstacles in securing jobs due to low proficiency in the English language. The majority of fresh graduates cannot speak and read well in English nor do they have good listening skills. Obviously, the appearance of this phenomenon indicates that our education system lacks the capability to develop and prepare our students for the needs of the job market, especially interacting in English. In addition, it also indicates the ineffectiveness of traditional approaches such as the teacher-centred approach which is currently practiced in the majority of Malaysian English Language Teaching (ELT) secondary homeschooling (Kunzman \&amp; Gaither, 2013). Consequently, there is a need to call for implementation of a more effective approach such as CLT in the Malaysian secondary English reading classrooms. Thus, it is crucial to investigate and record the secondary home-school students' opinions regarding the application of CLT in English reading classrooms before actually implementing the CLT approach. This highlights the significance of the present study.

The research by Richards \&amp; Rogers (2014), noticed that the majority of the secondary home-school students are not motivated to learn and engage themselves in English language activities such as reading. Most English teachers will try their best to motivate and encourage students to read in English but this has proven to be unsuccessful because most students will stick to their mother tongue language; Mandarin among the Chinese students and Malay among the Malay students. Most of the students will also focus on grammar rules, which they believe can help them to pass the examinations. As a result, the GrammarTranslation Method emerged as a popular language teaching method in teaching ESL, and applying mainly translation and grammar study as the main classroom activities. This method puts more focus on grammatical rules, vocabulary memorization, texts translations as well as performing written activities. Overemphasis on translation can neglect the listening and speaking skills of the ESL students. Mastering a lot of grammatical rules does not mean students can apply them appropriately and accurately in real communication situations. Most importantly, knowing grammar rules and having bilingual word lists is not going to motivate the students to actively communicate in the target language.

Besides that, the majority of secondary homeschooling students are unable to apply what they have learnt in the classrooms to the situational setting of their daily life (Kunzman \&amp; Gaither, 2013). The five years of secondary homeschooling may equip students with a substantial amount of linguistic knowledge on English, but they are still unable to read English fluently or listen and comprehend a text well. This low performing English language learners, especially in reading remains a problem until now. This has resulted in a need to conduct a research that focus on the effective implementation of CLT in secondary English reading home-schools.

In order to ensure effective implementation of CLT approach in reading, it is crucial that the CLT approach is firstly effectively and successfully implemented in the Malaysian secondary English reading classes to enhance the language proficiency especially oral competency among secondary homeschooling students. Specifically, since the research on this aspect in Malaysian secondary English reading classrooms have been scared, this study intends to fill the educational gaps (Littlewood, 2007).

\subsection{Research Objectives}

As a result of the expanding effect of globalization, communication in English has become increasingly extensive. Majority of the non-English speaking countries around the world are also more accepting of the English language. In order to prepare our secondary homeschooling students to be knowledgeable in national and international communication, there is a need for the effective implementation of CLT in Malaysian secondary English reading classrooms first. The objectives of this study are to investigate and observe students' perceptions of the use of CLT and to explore to what extent CLT approach contributes to improving ESL learners' reading skill. Hence, in order to achieve the research objectives, the following research questions are constructed: i. What are students' perceptions of the use of CLT in their reading classrooms?

ii. To what extent does CLT approach contribute to ESL learners' reading skill? 


\subsection{Significance of the study}

As in many ESL contexts, Malaysia has implemented the teacher-centred educational model for centuries. In order to employ this comparably new communicative approach in Malaysian secondary English reading classrooms, it is crucial and significant to investigate and examine how CLT has been implemented in such educational settings. So far not many studies have been conducted on secondary home-schools students' opinions about the application of CLT in their English reading classrooms. Hence, this study explores and investigates the students' perceptions of the use of CLT in their reading classrooms with the intention of recommending and suggesting that their opinions be considered prior to the decision to integrate CLT into the Malaysian secondary English reading classrooms (Savignon \&amp; Wang, 2003).

Based on the studies done by Wright (2000) on CLT in Malaysia, there is still a lack of or no empirical data on the secondary home-schools students' opinions about the application of CLT in English reading classrooms. As a result, there is a research gap that has to be addressed in the discussion on CLT application in the secondary home-schools English reading classroom. Therefore, as a researcher who strongly believe that there is a need to investigate the secondary home-schools students' opinions about the application of CLT in English reading classrooms with the intention to address this educational gap as well as provide resolutions to the educational gaps.

Since the unsuccessful implementation of CLT in 1970s, there has been a research conducted on teachers' attitude and beliefs in teaching English language in Malaysia (Radzi, Azmin, Zolhani, \&amp; Latif, 2007). Consequently, based on the information from the previous research, it is necessary to conduct a research to identify secondary home-schools students' opinions about the application of CLT as well as how it contributed to ESL learners' reading skill in order to ensure successful implementation of the $\mathrm{CLT}$ in Malaysian secondary English reading classrooms.

Upon completion of this study, it is hoped that the result of this study will benefit to the educational stakeholders, especially Ministry of Education of Malaysia to apply the result of the current study to improve the current curriculum to the Malaysian secondary homeschooling with the intention to improve the language proficiency among secondary homeschooling students.

\section{Literature Review}

\subsection{Introduction to $C L T$}

2.1.1. Communicative Language Teaching (CLT)

CLT originated from developments in the British Situational Language Teaching dating from the late 1960s (Kamhuber, 2010). It stems from the social-cognitive perspective of sociolinguistic theory which focuses on meaning and communication and a goal to develop the communicative competence of learners. The CLT approach has evolved as a prominent language teaching method and gradually replaced the previous Grammar- Translation Method and Audio-Lingual Method (Wright, 2000).

In response to the Grammar Translation Methods and Audio-Lingual Methods, British linguists introduced Communicative Language Teaching (CLT) in 1960s which then become an effective language teaching approach in 1970s. Halliday (1994) stated that at first CLT was designed for the ESL context, but was adopted in English speaking countries where English teachers supported a skill-based, discovery-oriented, and collaborative approach to education. A number of CLT based language courses and textbooks were introduced in second language learning (L2) with an emphasis at improving communicative competence of the learners. The intention of CLT was to provide the learners with opportunities to learn and apply the target language in L2 context. Therefore, the focus in language teaching shifted from drill-based language activities to communicative-based activities to provide a natural growth of language ability. CLT refers to both processes and goals in classroom learning. Identification of learners' communicative needs provided a base for curriculum design (Van Ek, 1975).

In the 1960s, CLT emerged from the West and has lengthened to the Eastern countries over the last 20 years (Chung, 2005: 33). It is regarded as an effective language teaching approach which is based on the justification that the significant function of language application is communication instead of focusing on grammar. As stated by Hymes (1972), the major aims of CLT are to develop communicative competence among the language learners. In other words, it is necessary to fully make use of real-life situations that require communication to be the outcome of CLT in order to enhance communicative ability. In teaching English as Second Language, CLT is the method that has put more emphasis on interaction as the final goal for language learning (Ying, 2010). Larsen-Freeman (2000) argued that CLT aims widely at the theoretical perspectives of a communicative approach from permissive communication.

The CLT places emphasis on developing communicative competence, viewed as "the overall underlying knowledge and ability for language use which the speaker-listener possess" (Celce, 2009). Through the communicative teaching, learners are encouraged 
to "consider language not only in terms of its structures (grammar and vocabulary), but also in terms of the communicative functions that it performs" (Kasim, 2015). By giving opportunities to use the language for real communicative purposes the teacher helps them to develop strategies relating the structures of a language to the communicative functions they can perform.

CLT is one of the approaches to second language education. It is an approach which views that second or foreign language teaching and learning should be based on promoting learners' communicative competence that involves the processes of expression, interpretation, and negotiation of meaning (Savignon, 2003). This indicates that CLT does not belong to any particular method of teaching; rather, it is an approach that can give insights to the incorporation of any methodologies as long as they promote communicative competence of the learners. In this regard, Savignon and Wang (2003) contend that the main nature of CLT emphasizes on \&\#39; the elaboration of programs and methodologies that promote the development of functional language ability through learner participation in communicative events\&\#39; (p. 230).

\subsubsection{Characteristics and Principles of CLT}

The CLT approach is a comparatively new approach that has become popular and widespread in the teaching English as second language in Malaysia. Wright (2007) stated that CLT is a hybrid approach to language teaching, essentially progressive rather than traditional. It can be seen that CLT is derived from a multidisciplinary perspective that included linguistics, psychology, philosophy, sociology and educational research (Rhalmi, 2009). It is commonly accepted that the proponents of CLT see it as an approach and not a method (Richards \&amp; Rodgers, 2014; Rhalmi, 2009; Brown, 2009). As stated by Brown (2009), CLT is a consolidated yet mainly based theoretical position on the nature of language and language learning and teaching. He further pointed out that the following four interconnected characteristics could be taken as a definition of

CLT:

i. All classroom goals are focused on all of the components of communicative competence and not restricted to grammatical or linguistic competence.

ii. Language teaching technique is designed to engage learners in the pragmatic, authentic, functional use of language for meaningful purposes and the language forms are not the central focus but rather aspects of language that enable the learner to accomplish these purposes.

iii. Ease of expression and correctness are perceived as integral standards fundamental communicative techniques. At times fluency may have to take on more importance than accuracy in order to keep learners meaningfully engaged in language use (Brown, 2009).

iv. In the communicative classroom, students ultimately have to use the language productively and receptively in unrehearsed contexts (Brown, 2009).

CLT can be susceptible to a variety of analyses and understandings as there is no single model of CLT that is universally accepted as authoritative nor is there a single text on this approach (Kamhuber, 2010). Some may regard CLT as an integration of functional and grammatical instruction while others perceive it as an instruction process that involves learners in problemsolving tasks through work in pairs or group work. According to Brown (2010), this approach consists of seven interconnected characteristics which are stated below:

a). A focus on all the components of communicative competence including discoursal, functional, grammatical, sociolinguistics, and strategic.

b). A focus on the authentic, pragmatic, functional use of language for meaningful purposes which does not neglect the significance of language forms.

c). A focus on both fluency and accuracy which are complementary and not mutually exclusive.

d). A focus on classroom tasks that prepare students with the fundamental and essential skills for communication in contexts outside the classroom.

e). A focus on cultivating independent learners who could continue to learn the language beyond the classroom contexts.

f). A focus on the role of teachers as a facilitator instead of a knowledge provider.

g). A focus on the role of the students as active participants in the classroom where emphasis is highly placed on cooperative and collaborative learning.

\subsection{Theoretical Framework and Conceptual Framework of CLT}

2.2.1. Lev Vygotsky (1978)

Social cultural theory describes learning as a social process that develops gradually through the integration of social, cultural and biological elements. As highly emphasized by Vygotsky (1978), social interaction plays a foundational role in cognition 
development. Based on this opinion, students manage to learn on two levels: (i) through their communication with others in an extensive range of activities and (2) by thinking deeply on new strategies and knowledge that have become assimilated into the mental structure of the students (Cross, 2010). His work places more emphasis on interaction, negotiation and collaboration amongst students in a social cultural context. Lev Vygotsky stated that:

Every function of the child's cultural development appears twice: first, on the social level, and later on the individual level; first, between people (inter psychological) and then inside the child (intra psychological). This applies equally to voluntary attention, to logical memory, and to the formation of concepts. All the higher functions originate as actual relationships between individuals (Vygotsky, 1978, p. 57).

As the learners engage in social interactions they start to internalize through active reasoning what they know with new ideas or concepts. One of the important features of learning recommended by Vygotsky (1978) is the zone of proximal development (ZPD) where learners play a comprehensive role in learning by interacting and working jointly with peers."Once these processes are internalized, they become part of the child's independent developmental achievement" (Vygotsky, 1978, p. 90). Language learning is a socially mediated learning process that involves experts or more knowledgeable others (MKO) and novices. Teachers should recognize that the role of expert is not limited to themselves only as it can shift to learners who have acquired an aspect of the language. Once the ZPD of the student is recognized, the MKO should provide guidance and encouragement to the further scaffolding of the students. As pointed out by Vygotsky (1978), students interpose their learning by collaborating, building up their private speech, and depending on gestures to communicate their concepts. As indicated by Vygotsky's work that Interaction and motivation amongst second language learners rise as learners start to internalize their L2 through play and social interaction activities (Vygotsky, 1978). Therefore, educators can categorize children appropriately and recognize specific interventions which can support the acquisition of $\mathrm{L} 2$ by identifying the learners' current development.

\subsubsection{Halliday and Wells on Language Learning}

The identification of seven functions of language by Halliday and Wells included instrumental, applied to express basic; regulatory, applied to give orders; interactional, applied to develop relationships; personal, applied to express feelings and opinions; heuristic, applied to understand the environment; imaginative, applied for storytelling; and representational, applied to convey facts and information (Halliday, 1975). Halliday (1969) defines language as a system for expressing meaning in context. It is therefore crucial for the students to play with language, practice amongst peers and access the rules of languages in order to improve language skills (Halliday, 1969). For example, role-play and pretend play manages to inspire learners in LF1 to enlarge their language knowledge.

Wells (2000) stated that the dialogic inquiry approaches to learning and teaching play a significant role in identifying the language development of children as a social and individual achievement. Children tend to build up their first language by listening, sharing and engaging with family, peers as well as caregivers. High exposure to a variety of contexts and discourses by the children allows them to begin to learn and recognize the forms and patterns of the language that exist in their community. Haneda and Wells (2008) felt that language is not encountered or learned as an abstract system of decontextualized rules and definitions. Rather, language occurs as a dialogue. Since this unnoticeable teaching about language cannot be easily depicted in the classroom, learning a second language among children requires diversified opportunities to employ in dialogic interactions in a variety of contexts with the intention of accessing their higher mental functions (Vygotsky, 1978; Wells, 2000). Wells (2007) affirms the significance of considering the requirements of the individual as well as the transactions carried out in a social environment. Learners may changeovers from colloquial discourse to academic discourse more comfortably by taking part in active spoken engagements.

As pointed out by Haneda and Wells (2008), children comfortably learn how to converse accordingly and to develop and understand utterances that achieve their motives. When learners work within their ZPD, they start to form a concept; "the many ways in which an individual's development may be assisted by other members of the culture, both in face-to-face interactions and through the legacy of artifacts that they have created" (Wells, 2000). It to be consistent with reason that encouraging learners to collaborate and create meaning through dialogue increases the regular use of speech genres and a larger diversity in the dialogues in which learners can participate. Particularly, the higher the exposure L2 learners have to a variety of discourses, the higher the opportunities that they able to participate in impulsive communication outside the classroom.

\subsubsection{Gees on Discourses}

Through examining communication with a cultural aspect, Gee (1990) has contributed considerably to first language (L1) and second language (L2) acquisition. He defines Discourse as "a sort of \&\#39;identity kit\&\#39; which comes complete with the 
appropriate costume and instructions in how to act, to talk, and often write, so as to take on a particular social role that others will recognize" (Gee, 1990, p. 142). The secondary Discourses are described as the interaction, including our words, acts, values, beliefs, attitudes, gestures, body position, we share with the community outside our home (Gee, 1989). According to Bialystok, Peets, and Moreno (2014), students develop language proficiency gradually as they master the structure of language, accumulate vocabulary, and develop efficient access to words and concepts.

Essentially, as the learners develop language, their secondary Discourses expand. ESL students will appealingly, with practice, confidently transfer this knowledge in a social context during communication. By developing fluency in L2, learners will more likely keep their listeners engaged, which will result in more exposure to the target language. For this exposure to happen, Gee (1989) emphasizes that the students need to be active participants in various Discourses in order to enable the learner to become fluent in several Discourses. Most L2 learners recognize that learning a language is not completely based on motivation but also on the influence of relationships and the power in the social world (Gee, 1989). Although students desire a sense of social belonging, if there is a conflict between students' primary Discourse and the Discourse in which they would like to participate in, full fluency will not be achieved and they will continue to be perceived as an outsider (Gee, 1990). For English Immersion to be successful, the learner should participate in authentic interactions with fluent speakers of the target language.

\subsection{Homeschooling}

Homeschooling can be explained with the word "home" and "schooling" which contributes the message instruction or education that happens at home. It is also a situation where parents create a attentive choice to supply an education for their children in place of that provided by schools, and where the parents are the main instructors in the education programme (Broadhurst, 1999). Considering homeschooling is a form of private education which is led by parents and home based, for that reason homeschooling does not depend on either state- run public schooling or institutional private schooling for a child's education (Ray, 2013).

Generally, homeschooling is a fresh form of alternative schooling in the education system in Malaysia. It is still at an initial stage of development (Norlidah, Mohd, Saedah \&amp; Ruslina, 2012). Anyway, the recognition and acceptance are developing throughout the years and this kind of schooling is to accept to evolve into the important adjustment of our lifestyle in the postmodern world. Therefore, aa survey toward homeschooling is crucial not only for parents and children who are homeschooling but also the prevailing instruction.

\subsection{English Language Proficiency Improvements Via Homeschooling}

Generally, all the homeschools apply English-medium education system which is one that applies English as the primary medium of instruction, particularly where English is not the mother tongue of the students. In this English-medium education system whereby English as a medium language to deliver instructions in all the subjects except language subjects such as Malay and Mandarin. Therefore, through the high exposure of English language among the secondary students, they manage to improve their English language proficiency. The argument in support of such English-medium policies is that teaching students subjects in English from an early age at the primary level will facilitate their smoother transition to secondary schooling as well as higher studies and will lead to higher levels of comprehension and 'use' of subject knowledge.

\subsection{CLT is Effective for Teaching of Reading}

Communicative approach provides definite influences to the teaching-learning process. It leads the learners active in reading English, comprehending the vocabulary, understanding the reading texts, performing the tasks, and studying well. By performing the task the learners could practice together in reading English actively, productively, and receptively.

The application of communicative language teaching (CLT) which includes group work and pair work. Group and pair work are approaches for collaborative education that provide the opportunity for social interaction among the students. Both approaches are class management strategy and the teachers play a significant role as a facilitator during teaching time. The role of teacher in group work is very challenging and in the intervening time it is pretty crucial role as well. Groups that are concentrated are a brief group of learners within a single class period. The groups of students can be consisted of three or four students who can group together to answer a reading problem or a reading question. The instructor can arrange these groups anytime in a reading class of any size to check on the comprehension of the students of the reading material, to provide learners the chance to apply what they are learning as well as bring change of pace.

Working together is beneficial and more favourable as "group and pair work directly boost the quantity of students talking time" (Wright, 2000). It is highly convinced by research workers that the learners who take the eagerness in learning, they manage to 
learn more things as well as learn much better than those students who learn passively from their teachers (Thamarana, 2015). In addition, researchers accounted that it is a origin of deep-seater inspiration for learners as actively occupied in groups is enjoyable and good for them. It supplies the chance for the learners to give or exchange ideas, information, insights, opinions as well as suggestions with each other. Furthermore, researchers further claim that the dominance of teachers in the class make it boring and it destroy the interest of the learners (Richards, 2006). On the other hands, pair work and group work equip the learners with collaborative activities to communicate in a new learning environment. Moreover, it also supplies them with chances to explicit themselves and thus they have a channel for mental state and can entertain during learning time.

\subsubsection{Reading Activities}

During reading classes, the learners were requested to read through the reading materials. They were advised to study through the reading material correctly to understand the comprehensive structure and meaning of the reading passage. The analyst explained in detail that the approach required learners to choose while reading the material. The reading activity was handled with a goal of boosting critical thinking among learners, which included ability to conclude, describe, discuss, elaborate, judge, narrate and negotiate. Besides advancing these capabilities there was an equal attention on grammar and vocabulary.

\subsection{Effectiveness of Homeschooling in Reading Improvement}

Homeschooling play a crucial role in reading improvement as they apply English-medium education system which English is used as main medium of language in delivery of instruction in all the subjects except language subjects such as Malay and Mandarin. In all the home schools, the instruction methods and communication inside the class rooms and homeschools regions are usually English which assist the progress of learners to rapidly achieve English competence among the students. Since English is the main medium of language, all the home schools students are compulsory to study English although it is not their mother tongue. Therefore, they need to improve the English language especially the reading skill in order to master the subjects such as Science, Maths, Biology, Chemistry and Physics, etc which requires comprehension of the theory in order to master the subjects.

\subsection{Theoretical and Conceptual Framework of Reading}

\subsubsection{Reading Skills}

As stated by Leipzig (2001), reading is a versatile and active process involving word recognition, comprehension, fluency and motivation. It is an interactive process in which the prior knowledge of a reader of the subject and intention for reading performed to affect what is learnt from the content. The visual structure of printed words and system by which letters symbolize speech sounds together characterize sub-processes used to recognize words. The word recognition processes are used briskly by articulate readers yet they may hamper readers with difficulties. As visual word arrangements are correlated with word meanings, a mental reorganization of complete textual meaning is constructed. This reorganization is subject to continuous adjustment and development as the reader improves. Ultimately, the closer the reorganized meaning is to the author's initially engaged message, the more favourable the act of communication will be. However, the goals of the readers may intentionally restrict the scope of reorganization as one reads an article in its indispensable content or confer books of facts for a particular fact. Based on this, the reading process can be defined as the reorganization cognitive meaning encoded in print.

In order to assist the progress of a student's effort to apply the reading process to acquire information on written materials, two major factors that the teacher should focus on which included the prior knowledge of the students and the objectives for which students will read. Understanding on what we read is deeply dependent on prior knowledge. Poor comprehension happens when the prior knowledge of a student of the covered content by a reading task is insufficient. Reading is continually purposeful. Therefore, the objective of a reader is to assist in deciding what information is finally studied, elucidated, recalled (Linderholm \& amp; Broek, 2002).

In terms of reading nature, there are two practical aspects which included the 'bottom-up' and the 'top-down' views (Harmer, 2001). The 'bottom-up' approach refers to the physical foundation of most reading courses. It is the belief that reading is essentially a matter of interpreting an array of written characters into something audible. The 'top-down' approach gives priority to meaning reorganization rather than the interpreting of form. Commonly, reading is an assimilation of both the processes.

\subsubsection{Collaborative Reading}

Collaborative Strategic Reading (CSR) is a research-based instructional practice in teaching reading comprehension to students to enhance content area learning (Bean, Readence \&amp; Baldwin, 2011). CSR instructs learners to read comprehension while working in small cooperative groups. It is mostly used with expository text, but can also be used with narrative text. The goals of CSR are to improve reading comprehension and increase conceptual learning in ways that maximize the involvement of learners. 
It is developed to enhance reading comprehension skills for students with learning disabilities and students at risk for reading difficulties, CSR has also yielded positive outcomes for average and high average achieving learners (Bean, Readence \&amp; Baldwin.

Basically, CSR consists of four major reading comprehension strategies that are applied before, during, and after reading. It includes four major steps below:

- Preview the text

- Click (I get it) and clunk (I don\&\#39;t get it)

- Get the gist (Skimming)

- Wrap up key ideas

(Bean, Readence \&amp; Baldwin, 2011)

\subsubsection{Before Reading: Preview the Text}

Students preview the entire passage before reading its sections. The objectives of previewing the text are to activate their prior knowledge about the topic, stimulates the interest of the learners about the topic and facilitates them to make predictions about what they will learn (Novita, 2012). Moreover, previewing the text also allows the students to learn as much about the passage as they can in a short period ( 2 - 3 minutes). During this step, students look at headings, keywords, pictures, and charts in a short period (Novita, 2012). The teacher asks students some questions to engage them in a classroom discussion about what they learned from the previews. Also, the teacher encourages students to predict what they think they will learn from reading (Novita, 2012).

\subsubsection{During Reading}

\subsection{Click and Clunk (I get it - I do not get it)}

Students click and clunk while reading each section of the passage. The goal of clicking and clunking is to teach students to monitor their reading comprehension and to identify when they have breakdowns in understanding (Bean, Readence \&amp; Baldwin, 2011). Clicks refer to portions of the text that make sense to the reader: \&quot;Click, click, click\&quot; - comprehension clicks into place as the reader proceeds smoothly through the text (Novita, 2012). When a student comes to a word, concept, or idea that does not make sense, \&quot;Clunk\&quot; - comprehension breaks down and make it hard to understand the whole text. For example, when students do not know the meaning of a word, it is a clunk. In this case, students need to identify the clunks then figure them out using fix-up strategies, written on clunk cards, to understand the text (Bean, Readence \&amp; Baldwin, 2011). Majority of the students with reading and learning difficulties are unable to monitor their understanding when they read. Therefore, click and clunk is a method that is designed to teach students to pay attention to when they are understanding - or failing to understand - what they are reading or what is being read to them (Novita, 2012).

\subsection{Get the Gist (Skimming)}

Students learn to identify the most important idea(s) in the text during reading. This strategy teaches students to re-state in their own words to explain the main ideas of every paragraph or two using a few words to check for understanding (Novita, 2012). In other words, teach students to provide the gist in as few words as possible while conveying the most meaning, leaving out details. This strategy can improve the understanding of the learners and memory of what they have learned from reading (Bean, Readence \&amp; Baldwin, 2011).

\subsubsection{After Reading: Wrapping Up}

After reading, students identify the most important ideas from the entire section they have read. They generate questions and answers about the information in the text. The goals are to improve students\&\#39; knowledge, understanding, and memory of what was read as well as encourage students to create high order thinking questions and write down the most important information in the text (Novita, 2012). The best way to teach wrap up is to tell students to use the following question starters to begin their questions: who, what, when, where, why, and how (the $5 \mathrm{Ws}$ and an $\mathrm{H}$ ). It is also a good idea to tell students to pretend they are teachers and to think of questions they would ask on a test to find out if their students really understood what they had read (Novita, 2012). Other students should try to answer the questions. If a question cannot be answered, that might mean it is not a good question and needs to be clarified. It is significant to encourage students to ask questions that involve higher-level thinking skills, rather than literal recall (Bean, Readence \&amp; Baldwin, 2011).

\subsubsection{Communicative Reading}

Communicative Reading is an instructional strategy "can be used to introduce a unit of instruction, to help explain a concept, to motivate students, and to simply provide enjoyment and appreciation of literature" (Goodmacher \&amp; Kajiura, 2010, p.48). 
"Communicative reading requires an appreciation of one's material as a work of literary art and the ability to communicate that work of art through voice and body. It demands full intellectual and emotional response from the interpreter, and a control and channeling of the understanding and emotion to elicit the appropriate response from the audience" (Goodmacher \&amp; Kajiura, 2010, p.48). In summary, communicative reading brings the words alive and provides the listener and even the reader with a vision. An example of communicative reading is reading a book aloud to the class in a group where it asks them to envision the story and the characters within it. The communicative reading consists of three major components which included communicative reader, audience and literary selection.

\subsubsection{Communicative Reader}

As the communicative reader, you are doing a variation of public speaking and the selection you choose to read is important because it provides insights to you, so you should choose something you enjoy reading so you can concentrate on your voice, eye contact, body movements and facial expressions to add to the instructional learning environment for your students (Goodmacher \&amp; Kajiura, 2010).

\subsubsection{Audience}

Knowing your students is imperative for this strategy to work, so that you pick a book or a story that is applicable to them and not too far fetched from their individual learning levels. Teachers also need to know where to cut a story, and what notes to make while reading aloud in order for your students to comprehend the material. In other words, you have to key into their listening skills, by using your listen skills to interpret if they will or will not understand the meaning behind this instructional technique (Goodmacher \&amp; Kajiura, 2010).

\subsubsection{Literary Selection}

The literary selection should be fully thought out to ensure it is appropriate for the lesson, students, time frame, and is beneficial to read aloud. Some literature is meant to be more of a self-read book rather than one to be read aloud. For example, reading the lliad aloud allows for students to comprehend the older English style of writing, while also allowing one to imagine the scenes within the book. When some students read alone, it can be harder for them to comprehend the lliad because of the complexity of the older English style of writing (Goodmacher \&amp; Kajiura, 2010).

\subsection{Adoption of CLT in ESL Reading Classroom}

Since its emergence in the 1970s, CLT has become extensive in English language teaching in ESL contexts (Paulista \&amp; Gomez, 2014). In order to increase the number of learners who managed to read effectively with English, the Ministry of Education should make a move toward the implementation of CLT in Malaysian secondary English reading classes. Ordinarily, the teaching of ESL has placed more emphasis on knowledge about the English language instead of the actual application of English for reading. The Grammar Translation Method and Audio-lingual Methods are two traditional approaches, which are commonly used for ELT (Paulista \&amp; Gomez, 2014). These two methods were accepted as not many people had the opportunity to apply English for real reading in ESL contexts. Nevertheless, due to the rapidly growing worldwide needs for business, travel and technology, ESL learners are now required to learn how to use English for reading purposes. The conventional methods as mentioned above no longer serve the needs of ESL learners. Therefore, it is time to change the traditional form-based method to a communicative-based one with stress on language functions and the needs of the learners (Paulista \&amp; Gomez, 2014).

\subsection{Advantages and Disadvantages of CLT}

\subsubsection{Advantages of CLT}

The application of CLT has accompanied a lot of benefits for teaching English as a foreign or second language. Unlike the traditional Audio Lingual and Grammar-Translation Methods, the Communicative approach places more emphasis on "taskoriented, student-centred" language teaching practice and it affords the learners with a inclusive application of English language, for communication of opportunities (Richards \&amp; Rogers, 2014). Besides that, CLT stimulates the learners to enhance their capability of applying English by themselves as CLT emphasizes on ease of expression in the target language. In other words, it supplies learners with tasks that enables them to advance their own opinions about what they are going to speak and how they are going to express. This allows the students to be more assured when interacting with other people and they also enjoy talking more (Brown, 2010).

Moreover, it also emphasizes on and targets at communicative ability. Thus, this enable the students to apply the language in a conversational position to content their requirements in actual connection is a first concern in CLT (Richards, 2006). That is to say, it carries the actual place of activity of the innate English into lecture room activities like presentation and imitation. 
Furthermore, the main section of the education course is not at the time the instructor hence exemplifying that CLT classes have switched from teacher-centeredness to learner-centeredness (Thamarana, 2015). That is to say, plenty of time expressed by the student that the function of the instructor is only to assist the progress of education course. Hence, the students should practice and connecting sufficient in the CLT class to accomplish communicative ability (Brown, 2010).

\subsubsection{Disadvantages of CLT}

However, there have been a lot of negative comments on the standards of the communicative approach to language education. One of the criticisms of this approach criticizes it as providing first concern to contexts and standards of application alternatively to language rules and structure rules. That is to say, it is perceived that there is insufficient focus on the adjustments of diction and language rules mistakes. This is as a result of excessive emphasis on contexts at the expense of form. It is admitted that with CLT there is a crisis of emphasizing excessive on spoken abilities with fewer attention is given to reading and writing skills (Thamarana, 2015).

In addition, the CLT approach places more emphasis on ease of expression but not correctness in language rules and pronunciation. As a result, communicative language teaching leads to the production of "articulate but erroneous" pupils (Kasim, 2015). Besides that, the CLT approach is excellent for average learners and progressive learners, yet not suitable for novices as few reserved routine is necessary. Learners with low competence in the aimed language can discover it hard to take part in spoken conversational activities and, if the tests applied by any academic are language rules based, communicative ease of expression may not be acceptable. Moreover, the supervising capability of the instructor must be excellent. In spite of the best efforts of teachers the lecture room activities are not truly actual and it can be hard to duplicate really genuine language application and to aid authentic interplay (Motteram, 2013).

Lastly, CLT is occasionally hard to be carried out in an ESL classroom as a result of deficiency of sources and apparatus such as genuine materials and innate talker instructors as well as huge sizes of the classes (Thamarana, 2015). Furthermore, appropriate classrooms are not ready for use that can grant for group work activities and for teaching aids and materials.

\section{Methodology}

\subsection{Introduction}

This chapter reports the research methods applied in this research. It will clarify the research methods and give a concise description of the selected participants and the data collection methods. This chapter will explain how the data were collected and analyzed.

\subsection{Research Design}

The mixed-mode research design was applied because the aims of this study were to investigate the students' perception of the application of CLT and how it contributes to improving the ESL learners' reading skills. Mixed- mode research is a research method for administering research which involves collecting, examining and assimilating quantitative and qualitative research (Palinkas, Aarons \&amp; Horwitz, 2011). This method provides great flexibility and manages to adapt many study designs such as observational studies to clear up more information than can be acquired in only a quantitative research. Besides that, this method reflects the viewpoints of participants whereby it provides a voice to study participants and to make sure that the research findings are based on the experiences of participants (Creswell, 2011).

Basically, the Likert-scale questionnaire is a cost-effective method to be used for data collection. By using this research method, a huge amount of in-depth information can be gathered from people in a short period of time and can be conducted by the researcher with restricted impact to its reliability and validity. Moreover, the outcome of the questionnaire can easily be quantified by the researcher whereby it can be used to compare and contrast with other research studies.

As stated by Dewalt and Dewalt (2002), the purpose of using classroom observation as a research tool is to build up a comprehensive understanding of the phenomena under study. It is suggested that classrooms observation be used as a technique to maximize the validity of the study as observations may assist the researcher to have an improved understanding of the context and phenomenon under study. In addition, it can be applied to provide the answer to the descriptive research questions to generate hypotheses (DeWalt \&amp; Dewalt, 2002). Observation checklist, field notes and voice recording will be systematically recorded during the classroom observation. 
A structured interview will be applied to gather the data from the participants to answer RQ 2. This research method can assist the researcher to gather valid and reliable data pertinent to the research questions and objectives (Cohen, 2011). This can support the RO in a more useful way compared to using questionnaires (Alexander, 2016). Cohen (2011) claimed that interviews have a higher response rate than questionnaires because respondents become more involved and are motivated in the structured interview. Structured interview questions based on the research questions will be prepared in order to elicit information which would reveal to what extent CLT approach contributes to ESL learners' reading skill. The researcher will adapt interview questions from

other research studies.

Pre-test and Post-test will be applied as a quantitative tool to measure the reading skills of the participants before and after administration of the treatment (Saunders, Lewis \&amp; Thornhill, 2009). The treatment involved the distribution of the past year's reading test paper to the participants for one week during which the participants are engaged in CLT reading classes. The purpose of the treatment is to measure their reading skills before and after a one week period. The result of the reading tests will be recorded and compared with another group of participants who have experienced the same reading test paper in order to improve the validity of the study (Sekaran \&amp; Bougie, 2010).

\subsection{Population, Samples, and Sampling}

3.3.1 Student Participants $(18,11)$

Eighteen secondary homeschooling students who have already been exposed to the CLT approach in their reading classrooms were selected as Student Participants (SP) of this study. All SPs are from Selangor homeschooling and thus represent ESL students of secondary homeschoolings. The selected homeschooling students have been exposed to CLT in their reading classrooms for more than three years. For the Control Group, eleven secondary homeschooling students from Right Bridge Learning Centre were involved in this study whereby no treatment is implemented in the English reading classes were selected.

\subsubsection{Participants for Classroom Observation Checklist (1)}

One English homeschooling teacher from Selangor secondary homeschooling volunteered to be observed for this research project. The Teacher Participant (TP) had implemented CLT as the main tool to deliver English instruction for more than 3 years. Field notes, checklist and voice recording were applied in this classroom observation in order to extract and analyze observational data since no lesson plans were obtained from the TPs.

\subsubsection{Students for Classroom Observation (2 Classes)}

The classroom observation which involved a total of 18 secondary homeschooling students from one class (lower secondary) as SPs was conducted for a period of two hours. The students will be labeled numerically upon data analysis and report (SP1, SP2, SP3 etc). For the Control Group, a total of 11 secondary homeschooling students from one class (upper secondary) as SPs was conducted for a period of one hour and forty-five minutes. The students will be labeled numerically upon data analysis and report (SP1, SP2, SP3 etc).

\subsubsection{Participants for Structured Interview}

\subsubsection{Home School Teachers (2)}

Two TPs were randomly selected for the structured interview. TPs selected for this study were ESL homeschooling teachers who had been teaching at secondary levels, had been exposed to CLT approach in ELT and had lots of teaching experience. These TPs had a minimum of 3 to 10 years experience in teaching ESL in Malaysian secondary homeschooling. In this study, two TPs who have had exposure to the CLT approach were interviewed for a period of two months.

\subsubsection{Home School Students (4)}

Out of the eighteen SPs, four SPs were also randomly selected for the structured interview. The selection of SPs is based on them being ESL homeschooling students who had been learning at secondary level, and had been exposed to CLT approach in ESL reading classrooms for at least 3 years. In this study, four SPs who had exposure to the CLT approach were interviewed for a period of two months.

\subsection{Location of Research}

The research obtained information in two Selangor home schools listed below:

Community Baptist Church Learning Centre (Experimental Group)

Right Bridge Learning Centre (Control Group) 
This study was conducted for a period of two months. Permission was requested from the principals before proceeding to the interviews and classroom observation with the secondary homeschooling teachers and students.

\subsection{Instrumentation}

3.5.1 Pilot study

As pointed out by Sekaran and Bougie (2010), a pilot study is a small scale introductory study such as a questionnaire and interview questions organized in order to examine feasibility, time and statistical variability in an effort to predict a proper sample size and improve upon the study design prior to performance of a full-scale research project. A pilot study is regarded as a crucial step prior to carrying out a full-fledged research.

A mixed-mode research method was employed in order to obtain an in-depth understanding of the ESL students' perceptions of the application of CLT approach and how it contributes to their reading skill. This included conducting interviews with both homeschooling teachers as well as students.

\subsubsection{Questionnaire}

In response to RQ1, a likert-scale questionnaire was administered to a total of 18 SPs from selected home schools. The questionnaire consists of four Parts. Part A deals with the demographic profile, Part B with the reading ability, Part C elicits information regarding students' perceptions on CLT and Part D investigates students' attitude toward English Language.

\subsubsection{Classroom Observation}

An essential element of classroom-based qualitative research is observation (Creswell, 2005; Mariam, 2004; Iwai, 2004; Azizah, 2002; Ely, 1991). Classroom observations were carried out by the researcher during CLT in the reading classrooms at homeschooling. An observation checklist was adapted from Kasim (2015) and pilot-tested before proceeding to the main research. This aims to investigate how instructors implemented CLT in the reading classroom. The observation checklist, field notes, and voice-recordings were systematically recorded during the classroom observation.

\subsubsection{Structured Interviews}

The first interview was conducted by the interviewers and the researcher. The main purpose of the structured interview is to ensure that each interview is presented with exactly the same questions and in the same order. This is to ensure that answers can be accurately aggregated so that comparisons can be created between sample subgroups (Elmusharaf, 2012). The selection of the interviewer for this structured interview was based on the application of CLT in ELT in secondary homeschooling. In this sense, it was possible to obtain responses with different perspectives and perceptions of how the CLT approach contributed to the ESL learners' reading skills from the homeschooling teachers. The interviews focused on qualitative research in a specific field and on investigating interviewees' perspectives. After the first structured interview, the pilot test was conducted on the interview questions so that they were clear in meaning. The interview was recorded and notes were taken.

Once the Pre-test reading was completed, a treatment was conducted on the SPs reading skill. In this experiment, the reading test was conducted for one week during which the SPs were engaged in CLT reading classes using the same reading test paper.

\subsubsection{Pre-test and Post-test Reading Paper}

Pre-test and Post-test designs are considered favorable methods to compare participant groups and to calculate the degree of change occurring as a result of treatments. In this study, the Pre-test involved applying a past year reading test paper $\left(\mathrm{O}^{\prime}\right.$ level English Reading Paper A, 2015) to test the reading skills of18 student participants (SPs) before any treatments are intervened and the result of the reading test was recorded. After intervention of the treatment which involved the implementation of CLT in ESL reading classes, a post-test was carried out in order to examine the reading skills of the 18 SPs after intervention of the treatment. The reading test result was recorded and a comparison was made with the Pre-test result. Figure 3.2 presents an overview of the methodology of this study.

\begin{tabular}{|l|l|l|l|l|}
\hline No & Data Type & Analysis & Instrument & Remarks \\
\hline 1 & Pre-test \& Post-test & Quantitative & Past year reading paper & $\begin{array}{l}\text { Paper from: } \\
\text { O' level English } \\
\text { Reading Paper A } \\
(2015)\end{array}$ \\
\hline 2 & Observation & Qualitative & 1. Checklist & $\begin{array}{l}\text { Adapted from: } \\
\text { - Kasim (2015) }\end{array}$ \\
\hline
\end{tabular}




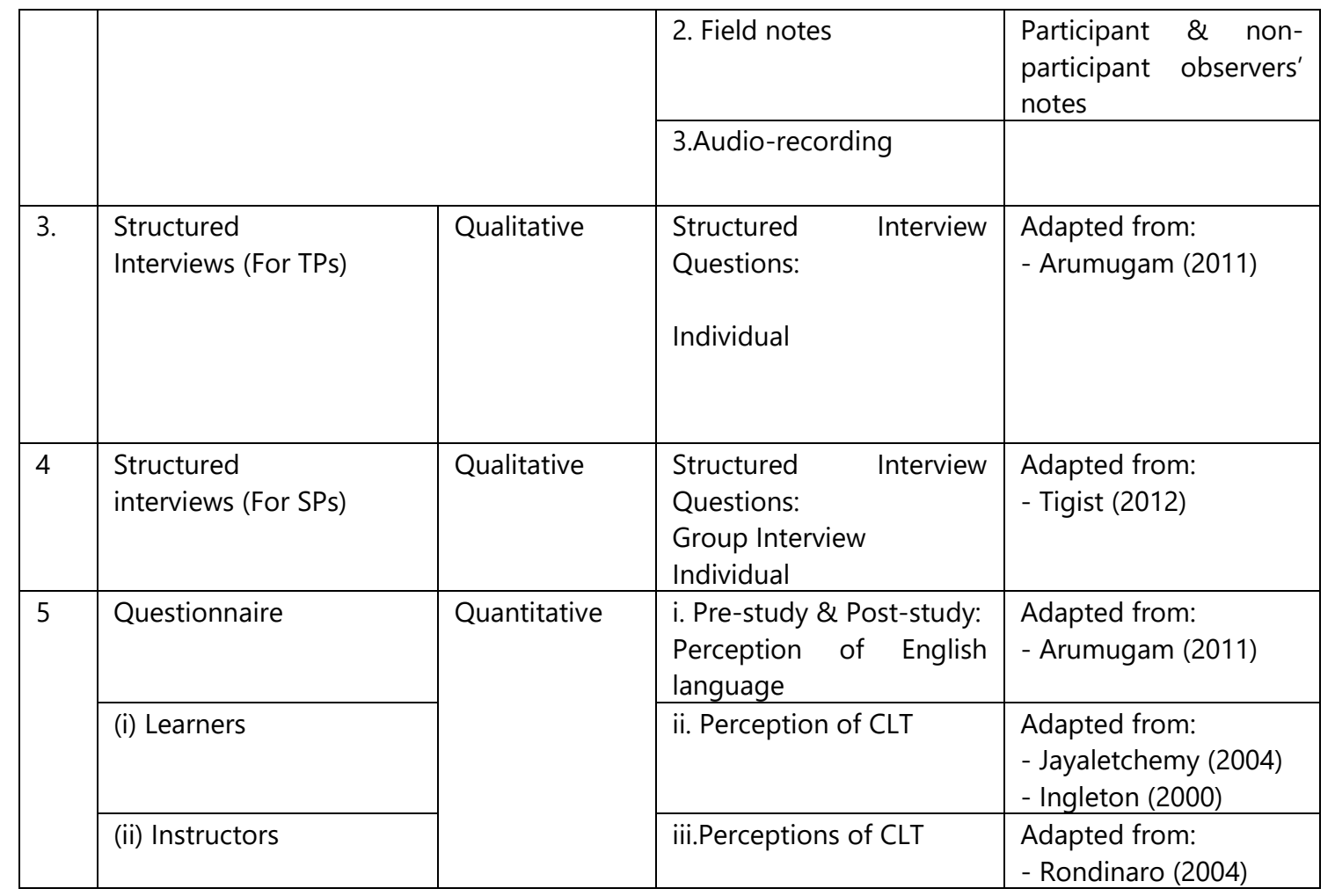

Table 3.1 : Schedules of Data Type and Procedures

Study plays a crucial role in determining the success of research projects. A pilot study allows for the introductory testing of theories that leads to the testing of more accurate theories in research projects. Besides that, it usually provides the researchers with approaches, clues, and ideas that may not have been expected before conducting the pilot study. In addition, it enables a comprehensive inspection of the prepared statistical analytical procedures, providing us an opportunity to judge their practicality for the data (Newby, 2010).

It is crucial to pilot test the questionnaire and interview questions in order to improve the validity and reliability of the questions. In this study, a pilot test was carried out in one selected homeschooling to find out the achievability and validity of interview questions and questionnaire. The pilot test involved a smaller group of secondary homeschooling teachers as the researcher only required their crucial responses in relation to the interview questions if they manage to provide appropriate responses from the homeschooling teachers. The pilot test was administered at the early stage of this study in order to get the data collected ready for analysis.

Five randomly selected TPs were given a questionnaire in this pilot test. Upon collecting their responses, some appropriate adjustments were required to reconstruct the questionnaire items as the feedback provided by the TPs did not achieve the research objectives. The majority of the TPs realized that the questionnaire was too wordy and a verbal response was instead highly preferred.

Thus, new items for the questionnaire were created to make sure that the research objectives could be achieved. At the same time, the desired adjustments made on the questionnaire and interview questions allowed for more valid data to be obtained and analyzed (Cohen, Manion \&amp; Morrison, 2011).

\subsection{Data Collection}

Both the qualitative and quantitative methods for data collection and analysis were conducted by the researcher. Interviews were recorded with the permission of the instructors in order to enhance the validity and reliability of the data collection process. The data collection also consisted of field notes from observation. Table 3.2 below exhibits the type and the procedures employed in collecting data.

For RQ 1, the likert-scale questionnaire was applied in order to gather in-depth data on the students' attitudes, experiences, beliefs, perception and understanding of SPs. Moreover, the outcome of the questionnaire was easily quantified by the 
researcher whereby it could be used to compare and contrast with other studies. Besides the likert-scale questionnaire, observation was used as a tool to gather qualitative data in response to RQ 1. In this research, classroom observation was carried out and it allowed the researcher to study the routine activities of the people under study in the research setting through discovering and taking part in those activities (DeWalt, \&amp; Dewalt, 2002).

The comparison between Pre-test and Post-test elicited information and data to answer RQ 1. The structured interview was applied to gather data from the participants in order to answer RQ 2. This research method assisted the researcher to gather valid and reliable data pertinent to the research questions and objectives (Bryman, 2012; Cohen, 2011). The interviews focused on a specific field and concentrated on investigating interviewees' perspectives. Three English homeschooling teachers were selected from secondary homeschooling for the structured interview. The initial selection invited junior to senior English teachers in homeschooling, teachers who graduated from abroad and teachers who graduated from Malaysia so that different points of view of the same topic and working environment were heard. During the interview, note-taking was used about the interviewee's body language or eye contact when the topics were given.

\subsection{Data Analysis}

Based on Newby (2010), data analysis in a mixed-method research consists of analyzing the quantitative data using quantitative methods and the qualitative data using qualitative methods. In this study, a mixed-methods analysis applied multiple designs which included the likert-scale questionnaire, classroom observation, structured interviews as well as a quasi-experimental one. In short, it involves the orderly integration of distinctive data drawn from different designs. Consequently, advanced planning and careful management are highly required by a mixed-methods analysis.

RQ 1 requires quantitative responses which involved the pre-test and post-test method. The question (RQ 1) was analyzed by eliciting information from the SPs sample in the study. Dependent t-Test (Two-tailed Test) was conducted to evaluate the impact of the treatment on students' reading competence by comparing the pre and post-test grading of SPs (Arumugam, 2011; Iwai, 2004; Massey, 2003). Moreover, it was also suggested (Sekaran, 2002) that pre and post-test conducted within a group should be tested using Dependent t-Test to observe effectiveness. The questionnaire was analyzed using the percentile. The second research question (RQ 2) was answered using structured interviews in order to triangulate the findings. A summary of methods applied in data collection and data analysis is presented in Table 3.3.

\begin{tabular}{|c|c|c|}
\hline Instrumentation & Data Collection Method & Data Analysis Method \\
\hline 1. Questionnaire & Personal Collection & $\begin{array}{l}>\text { Data was converted to percentage. } \\
\text { Data from Questionnaire will attempt to } \\
\text { answer RQ 2. }\end{array}$ \\
\hline $\begin{array}{l}2 . \\
\text { Observation }\end{array}$ & $\begin{array}{ll}> & \text { Personal Observation } \\
> & \text { Checklist }\end{array}$ & $\begin{array}{l}\text { Observation will be conducted using a } \\
\text { checklist. } \\
\text { Data from observation attempts to answer RQ } \\
\text { I. } \\
\text { Significant parts of the classroom } \\
\text { observations will be presented via excerpts } \\
\text { and the data will be interpreted and } \\
\text { discussed. }\end{array}$ \\
\hline 3. Structured Interview & $\begin{array}{ll}> & \text { Face to face } \\
> & \text { Email } \\
> & \text { Mobile phone }\end{array}$ & $\begin{array}{l}\text { Interview responses will be recorded via note- } \\
\text { taking and audio-recording. } \\
\text { Participants' own words are incorporated in } \\
\text { the analysis. } \\
>\quad \text { Data from students interview attempt to } \\
\text { answer RQ 1. } \\
>\quad \text { Data from teachers interview attempt to } \\
\text { answer RQ 2. }\end{array}$ \\
\hline
\end{tabular}

Table 3.1: A Summary of Methods Applied in Data Collection and Data Analysis

\subsubsection{Validity and Reliability}

The validity of the study was strengthened by securing data from a number of diverse instruments. Second, the audio recordings of the structured interviews were analyzed repeatedly (at least three times) by paying attention to SPs and TPs' responses. This would curtail and limit any misinterpretation and misunderstanding on the part of the researcher. The next measure to 
strengthen validity was taken by having non-participant TPs' opinions and judgments while conducting the observation and structured interview. Lastly, the pre-test and post-test scripts were evaluated by a non-participant instructor using an established Analytic Scoring Guide which was used by the institution.

\subsection{Demographic Profile of the Teachers}

Two English homeschools teachers involved in this research; one female and one male teacher. One of the male homeschool teachers had more than 20 years of teaching experience in secondary schools and was teaching at high school level in Right Bridge Learning Center located in Bandar Puteri, Puchong. He normally deals with a small number of students in one class which is about 11 students in one class. Besides that, one of the female homeschools teacher who holds a Master in Linguistics had less than 10 years of experience in ELT and was teaching in a high school in CBC Learning centre. She normally deals with a bigger number of students in her class 18 students. Both considered themselves as speakers of English as a second language.

\section{Results and Discussion}

\subsection{Introduction}

The results of this study were obtained through a questionnaire where the participants were the students and home-schools teachers who were directly involved with the Communicative Language Teaching Approach at a practical level. During the period of the investigation, the researcher communicated with them formally and informally. The formal investigation consisted of questionnaires for the home-schools students and teachers. The informal investigation was accomplished through observation and interviews with students and teachers of different home-schools. Participation of the home-schools students and teachers was spontaneous. The results are discussed and analyzed based on research questions and research objectives. First, results of classroom observation and student interview responses are presented. Similarly, the results of Pre-test and Post-test as well as students' questionnaire are presented. Finally, the results of the teachers' questionnaire survey and teachers' interviews are presented. All these results will answer the following research questions:

(i). What are students' perceptions of the use of CLT in their reading classrooms ?

(ii). To what extent does the CLT approach contribute to ESL learners' reading skill ?

A summary of the findings and discussion is presented at the end of this chapter. The first Research Question discusses the students' perceptions of the use of CLT in their reading classrooms.

\subsection{ESL Learners' Perceptions of the use of CLT in the Reading Class}

\section{Research Question 1:}

What are students' perceptions of the use of CLT in their reading classrooms?

This question intends to analyse the effectiveness of an instructional method called Communicative Language Teaching (CLT) for the teaching and learning of English as a Second Language. Specifically, this study investigated whether there was a significant difference in the reading achievements of the learners before and after the implementation of CLT approach in the teaching of reading skills.

\subsubsection{Students' Perceptions Of CLT}

In terms of the students' perception of CLT, $100 \%$ of home-schools students from the Experimental Group found that CLT was highly effective in improving general academic achievements, higher level thinking skills, interest in the subject matter, likelihood of their attending class, frequency and quality of contact with teacher, percentage of class time that they are paying attention, ability to diagnose their own knowledge of subject matter, frequency and quality of interactions with their classmates and amount of class time necessary to reach mastery of a concept. Besides that, only $83.33 \%$ and $94.44 \%$ of them stated that CLT was highly effective in improving general the Experimental Group strongly agreed that it was a new teaching method to meet the demands of the times, has emphasis on interpersonal skills, better than the traditional method of stimulating students' interest in learning. Moreover, $88.89 \%$ of them strongly agreed that CLT stimulated students to communicate their enthusiasm.Also, 83.33\% of them strongly agreed that it was than trying to teach the entire language is more formal system of traditional law quick, but also save time and effort. Furthermore, all the students from Experimental Group strongly agreed that the role of CLT was to get students together to brainstorm, whereby students got to learn from one another.

Generally, all the students tend to have a positive and motivated learning experience in the Communicative approach as it helped them learn reading in English. Communicative approaches such as group discussions and presentations helped them improve their vocabulary and comprehension of the given passages through interacting and sharing of ideas and opinions with each other in the group discussion. In addition, positive attitudes such as self-discipline, self-responsibility, self-motivation and 
self-confidence can be developed through the group work. In short, communicative activities are more lively and interesting compared to their regular traditional English classroom activities. As pointed out by the interviewees below CLT managed to help them improve their ESL reading skills. They said, "During group discussions, we were able to learn more from each other when learning new vocabulary during the reading class as well as improve our pronunciation when we try to communicate with other group members." (Interviewee 14) "In terms of reading, we learnt more vocabulary through group discussions and improve our reading comprehension when we discussed with our group members. It work effectively and positively for the outspoken students whereby they were able to communicate well by giving creative ideas and opinions on certain topics." (Interviewee 9)

\subsubsection{Students' Responses Regarding CLT \\ Learner Perceptions within Setting}

To investigate the learners' perception of reading skills, the following items were analysed (Appendix D). The questionnaire was divided into four major categories which included academic achievement, social benefits, generic skills and finally negative aspects of CLT. Later the responses were merged into two major groups which included strongly agree and agree for agreed responses and strongly disagree and disagree for disagreed responses.

As asserted by Brown (2010), learners from the Experimental Group demonstrated the positive outcomes of CLT in reading skills. In the Experimental Group, in terms of academic achievements, it can be seen that $100 \%$ of home-schools students from the Experimental Group perceived CLT to be helpful in understanding reading texts and improving academic performance while receiving useful or helpful feedback. Besides that, $90 \%$ of them responded that it enabled learners to help weaker learners in the group, and $87 \%$ of them said that learners actively participated in the teaching or learning process and improved their performance. Furthermore, $82 \%$ of them felt that it fostered exchange of knowledge, information and experiences. As highlighted by previous studies, while CLT facilitated academic advancement of learners, the current study further strengthens the role of CLT in academic performance (Assefa, 2012; Kasim, 2015; Littlewood, 2007).

In terms of social benefits, $100 \%$ of students from the Experimental Group strongly agreed that CLT enabled them to make new friends and that CLT should be continued. Moreover, $95 \%$ of the students strongly agreed that they learnt in a more relaxed atmosphere and $89 \%$ of them agreed that it was fun.

In terms of generic skills, $100 \%$ of the students from the Experimental Group strongly agreed that CLT allowed them to focus on collective efforts rather individual ones and $94 \%$ of them highly agreed that it enhances communication skills as well as fosters team spirit. Furthermore, $92 \%$ and $91 \%$ of them strongly agreed that it made problem-solving easier and taught them to have greater responsibility for themselves and the group.

However, on the negative aspects of CLT, 70\% of the students from the Experimental Group disagreed that CLT was a waste of time spent on explaining things to others. $59 \%$ of them disagreed that it was difficult getting students to actively participate in tasks. On the other hand, $67 \%$ of them agreed that not all students engaged in the CLT approach.

\subsection{3 : Reading Capability of Learners Before and After Treatment}

The result shown that some of home-schools students tended to have a negative reading ability before the implementation of treatment, whereby $88.89 \%$ of students from the Experimental Group made mistakes when they read in English. Besides that, $55.56 \%$ of students from the Experimental Group agreed that they could remember some of the grammar rules as they read. Before implementation of the treatment, $44.44 \%$ of students from the Experimental Group agreed that they could read better in English with the help of their group members. In addition, 88.89\% from the Experimental Group agreed that they enjoy reading in English. Besides that, 38.89\% of students from the Experimental Group agreed that they like reading English newspapers and/or magazines. Furthermore, only 5.56\% from Experimental Group agreed that they did not have any desire to read in English even if the content was interesting. Moreover, only $27.78 \%$ from Experimental Group agreed that they would not voluntarily read in English unless it was required as homework or assignment. After implementation of the treatment, it can be noticed that the majority of home-schools students from the Experimental Group tend to have a positive reading the Experimental Group agreed that they could remember some of the grammar rules as they read. In addition, $88.89 \%$ of them strongly agreed that they could read better in English with the help of their group members and they enjoyed reading in English. In addition, the students from the Experimental Group tend to have a positive reading ability whereby $94.44 \%$ of students from Experimental Group strongly agreed that they liked reading English newspapers and/or magazines However, 27.78\% of the students from the Experimental Group agreed that they did not have any desire to read in English even if the content was interesting. Lastly, 38.89\% of students from the Experimental Group agreed that they would not voluntarily read in English unless it was required as homework or assignment. 


\subsection{4 : Enjoyment in the Communicative Approach}

Basically, the majority of students enjoyed working in group discussions and they pointed out that they could communicate their ideas and opinions with their group members from different backgrounds and this allowed them to share and exchange different points of view on particular topics. At the same time, they got to learn more different ideas and opinions on the given topics through the group discussion. One student said, "I prefer group discussions as we can share and exchange our ideas and opinions with everyone in the group and get to learn more different ideas and opinions on the given topics." Another student shared, "love and enjoy to share and exchange our ideas and opinions with other students during group discussion."

\subsection{5: The Interests on the Communicative Approach}

Based on the interview data, the students found the Communicative approach a pretty interesting approach in learning the English language. They prefer this student-centred approach as it enables them to learn something by themselves first before asking for clarification from their teachers. So, they found that the approach very interesting and effective in learning English. Moreover, they perceived that it was a good way to learn English because they were able to learn more through this approach than the traditional method. They also found that this approach is more effective and useful in learning English. They said,

"We find this approach interesting as it is a student-centred

method in learning English language. For us, we prefer to learn

something by ourselves first before we ask our teachers for clarification.

So, we find that this approach is very interesting."

(Interviewees 15, female and male)

"We think that it is a good way to learn English because

we were able to learn more through this approach rather than the traditional

method. We find that this approach is more effective and useful in

learning the English language."

(Interviewees 15, female and male)

\subsubsection{Teachers' Perceptions of CLT}

Basically, the home schools teachers have a positive perception of the CLT approach. They strongly agreed that it was an effective and useful teaching method to meet the demands of the time as this method puts high emphasis on interpersonal skills, stimulates the students to communicate their enthusiasm as well as their interest in the learning process. Therefore, they will increase usage of CLT in the reading classrooms.

A teacher respondent shared:

"In my personal opinion, CLT is effective in teaching reading, I strongly agree with that because it is not the traditional way, it's something like a student-centred effort. It is a new teaching method to meet the demands of the times, it emphasizes interpersonal skills, is better than the traditional method of stimulating students has interest in learning, and stimulate students to communicate their enthusiasm. Although we work as teachers, we need to know what the students actually want, and not just teach them. They should know their expectations from us, so it is a better method to teach English reading in the ESL context. They can apply in their learning through this method."

Another teacher respondent said that students who were much more proficient than the others were definitely more committed to it. The others seemed to struggle a little as quite a number of my students came from Chinese schools so the language barrier can be quite a struggle in actually handling the situation. She said,

Some of them who are very proficient in language are able to express their ideas clearly, the others might struggle a little bit yet they try their best to actually express their ideas. So far I notice that throughout the time, they have manage to express their ideas as they know what to express in the comprehension questions. The main problem is their language barrier and their understanding of the passage may not be accurate. 
Basically, it was observed that the students with good language proficiency are actively engaged and participated quite well in communicative activities such as group discussions, presentations, etc. They manage to express their ideas and opinions clearly. On the other hand, students with low language proficiency struggled in these communicative activities as they were unable to express their ideas and opinions clearly due to the language barrier that they encountered. The majority of the students came from Chinese schools and were more comfortable using their mother tongue since young. As a result, many of these students were unable to communicate well in English and this had caused them not to actively participate in the communicative activities.

In addition, one of the teacher respondents pointed out her role in CLT. whereby she highlighted that she will assume to be the person who actually start the communicative-based learning, to actually guide the students on their learning probably on the communicative structure. In reading, the role of CLT is more about comprehension, to know that what they read can be progressed into speaking, writing, in the form that they should understand the passage is not just a given paragraph that they should actually read. Therefore, she'll increase usage of CLT.

Both the interviewees strongly agreed that the communicative approach play a significant role in language learning, especially in reading. CLT is a student-centered method which manage to guide the students on their language learning pathway and allow them to learn more as compared to the traditional method.

In the communicative reading classrooms, the secondary homeschooling students are becoming more active in their role as learners as well as readers and are playing a significant role in many aspects of the English reading classes. One of the meaningful advancement is the quantity of learner input and decision-making that commonly occurs in the unit development. In the introductory phase of a reading unit, the readers are requested for their input and the information that they have on a specific reading subject. It is this input phase that initiate the motivation of the students. They are highly encouraged to create plenty of decisions whereby they required to choose what vocabulary and passage structures are crucial for their reading activities. Their decisions concerning the reading activities reflect the interest and strengths of the readers. The readers who are acknowledged some opportunity to read within the parameter are more probable to stay motivated as well as stay on reading tasks.

At the end of the reading classes, the practical objective provides the learners and readers the favourable circumstances to work toward their potential. Since the readers aware of this reading project in the initial stages of the reading unit, they are then manage to tailor their vocabulary, their reading activities and their thinking toward the final task. The readers are much more willing to stay on reading tasks as they find out that the work they do within the reading class leads them toward their ultimate objective. The readers have the capabilities to embody their reading projects and apply their personal strengths and talents. The learners with powerful English reading background may wish to extend on the oral or written aspects of the reading projects. Learners with a lesser degree of language skill will also be able to work toward their own potential. Students learn in distinctive ways and at a diverse pace and their reading projects reflect these unique distinctions.

It was showed in the structure interview that most of the time, the homeschooling teacher allow group members to earn rewards (such as certificates or other forms of recognition) if all group members improve their performance on quizzes or other means of evaluation and set up an evaluation system where students working in groups are assessed individually regardless of group performance. Besides that, about half of the time, she assigns students to groups based on criteria such as: academic ability, gender, grades, etc and set up groups so that members are working toward common instructional goals. Sometimes, she allows students to select their own group members during group discussions. Moreover, she always have students work in groups and set up face to face interaction in which they help, support, and encourage each other's efforts to learn. In setting up groups so that there is an atmosphere of interdependence that is each member thinks that he/she will not succeed unless group mates also succeed and the members are working toward common instructional goals as well as teach social skills to students before and /or during group interaction, the teacher practice it most of the time. Lastly, most of the time the teacher has given students feedback about the group interaction experience during and /or at the end of group activity.

Basically, the home-schools students tend to have a positive and motivated perception on the application of communicative approach in reading classrooms whereby they find that this approach help them to learn English reading more effectively and efficiently. Through this approach, they manage to learn more new vocabulary and have a better understandings on the assigned passage through group discussions with their group members.

On the other hands, the students in the control group unable to perform well as no treatment is implemented in the control group. The students managed to perform moderately in the reading tests as compared to the experimental group.

The following research question will discuss the contributions of CLT to ESL learners' reading skill. 


\subsection{CLT Approach and ESL Reading Performance}

Research Question 2

To what extent does CLT approach contribute to ESL learners' reading skill?

Basically, the result of the Pre-test and Post-test was analysed to measure the reading skills of the participants before and after administration of the treatment (Saunders, Lewis \& Thornhill, 2009). Besides that, the students and teachers' structured interview responses helped to answer RQ 2.

Table 4.1 : Mean of Pre-test and Post-test of Students: Experimental Group

\begin{tabular}{|l|l|l|l|l|}
\hline & Frequency & $\begin{array}{l}\text { Mean } \\
(\mathrm{M})\end{array}$ & $\begin{array}{l}\text { Standard } \\
\text { Deviation (SD) }\end{array}$ & $t$ value \\
\hline Pre-test & \multirow{2}{*}{18} & 37.78 & 9.79 & 2.86 \\
\cline { 1 - 3 } Post-test & & 70.22 & 12.53 & \\
\hline
\end{tabular}

The Pre-test and Post-test reading performance of the students was first analysed according to their overall test scores using paired-samples t tests. The scores showed statistically significant improvement in scores from Pre-test $(M=37.78, S D=9.79)$ to Post-test $(M=70.22, S D=12.53)$. Therefore, it can be concluded that there was a significant difference between the Pre-test and Post-test scores among the learners. The low significance value for the $t$ test $p=2.86$, indicated that there was a significant difference between the two variables. Thus, it indicated that the learners who were taught employing the CLT approach in the ESL reading class performed well. In general, the results in the Experimental Group showed that there was significant improvement among the learners between pre and post-test scores. Therefore, we can conclude that there was a significant improvement in scores between pre-test to post-test scores.

Table 4.2 : Mean of Pre-test and Post-test of Students from Control Group

\begin{tabular}{|l|l|l|l|l|}
\hline & Frequency & $\begin{array}{l}\text { Mean } \\
(\mathrm{M})\end{array}$ & $\begin{array}{l}\text { Standard } \\
\text { Deviation (SD) }\end{array}$ & $t$ value \\
\cline { 1 - 4 } Pre-test & \multirow{2}{*}{11} & 77.45 & 6.02 & \multirow{2}{*}{4.13} \\
\cline { 1 - 3 } Post-test & & 91.64 & 8.94 & \\
\hline
\end{tabular}

Table 4.5 shows the paired-sample t-test conducted to evaluate the impact of the intervention on the students' scores on the CLT reading skill. The learners showed a statistically insignificant improvement in scores from Pre-test $(M=77.45, S D=6.02)$ to Post-test $(M=91.64, S D=8.94)$. The high significance value for the $t$ test $p=4.13$, indicated that there was an insignificant difference between the two variables. Therefore, it can be concluded that there was an insignificant difference between the Pretest and Post-test scores among the students in the Control Group.

As highlighted in the literature review, the implementation of CLT has brought a lot of advantages to Teaching English as a Second Language (TESL). Unlike the traditional audio lingual and grammar-translation methods, the Communicative approach places more emphasis on "task-oriented, student-centred" language teaching practice and provides the students with a comprehensive use of English language, for communication of opportunities (Richards \& Rogers, 2014).

Besides that, it motivates students to improve their ability to use English by themselves since it emphasizes fluency in the target language. In other words, it provides students with assignments that allow them to improve their own ideas about what they are going to talk and how they are going to express. This enables the learners to be more confident when interacting with other people and they also enjoy talking more (Brown, 2010).

\subsection{Result of Dependent $t$-Test Between Pre-test and Post-test Scores}

\subsubsection{Experimental Group}

The table above shows the students who were unable to score well in the Pre-test or failed the reading test. Four students managed to pass the reading test. On the other hand, after implementation of the treatment, all the students showed a bigger improvement in the Post-test. All of them managed to pass the reading test with better results as compared to the Pre-test result. This indicated that CLT is an effective approach in teaching ESL reading classrooms. 
The significance level (alpha level, $\alpha$ ) is 0.05 . With degree of freedom, $d f=N-1$ (refer to t-table) $18-1=17$, thus the critical value equals \pm 2.11 for $\alpha=0.05$. SD is the standard error of the difference between two means when observation are-paired. It is calculated from the following formula:

$S_{\bar{D}}=\sqrt{\frac{\sum D^{2}-\frac{\sum D^{2}}{N}}{N(N-1)}}$

where $\Sigma D^{2}=$ sum of the squared differences scores

$\Sigma D=$ sum of the difference scores

$N=$ number of pairs

$=\sqrt{\frac{19839-\frac{19839}{18}}{18(17)}}$

$=\sqrt{\frac{18736.83}{306}}$

$=\sqrt{61.23}$

$=7.82$

The full formula for $t$ when the samples are dependent is as shown below:

$$
t=\frac{\bar{D}}{\sqrt{\frac{\sum D_{2}-\frac{\left(\sum X\right)_{2}}{N}}{N(N-1)}}}
$$

$=\sqrt{\frac{32.28}{7.82}}$

$=4.13$

Based on the result above, $t=4.13$ with $d f=N-1$

$18-1=17$. Therefore, the obtained value of $t$ is bigger than the critical values, \pm 2.11 . Thus the result is significant at the 0.05 level. The conclusion is there is sufficient evidence to conclude statistically that the two sets of tests strongly affect the English reading skills among the ESL secondary homeschooling students in Malaysia.

4.3.1.2. Control Group

Table 4.3 : Data for Dependent t-test - Reading Performance Based on Two Sets of Test

\begin{tabular}{|c|c|c|c|c|}
\hline \multirow{2}{*}{$\begin{array}{l}\text { STUDENT } \\
\text { PARTICIPANTS }\end{array}$} & \multicolumn{4}{|c|}{ MARK (\%) } \\
\hline & Pre-test & Post-test & Differences $(D)$ & $D^{2}$ \\
\hline SP 1 & 60 & 92 & 32 & 1024 \\
\hline SP 2 & 79 & 92 & 13 & 169 \\
\hline
\end{tabular}




\begin{tabular}{|c|c|c|c|c|}
\hline SP 3 & 84 & 92 & 8 & 64 \\
\hline SP 4 & 75 & 96 & 21 & 441 \\
\hline SP 5 & 69 & 96 & 27 & 729 \\
\hline SP 6 & 89 & 96 & 7 & 49 \\
\hline SP 7 & 77 & 92 & 15 & 225 \\
\hline SP 8 & 73 & 80 & 7 & 49 \\
\hline SP 9 & 91 & 100 & 9 & 81 \\
\hline SP 10 & 85 & 92 & 7 & 49 \\
\hline \multirow[t]{2}{*}{ SP 11} & 70 & 80 & 10 & 100 \\
\hline & & & $\begin{array}{l}\Sigma D=156 \\
D=14.18\end{array}$ & $\Sigma D^{2}=2980$ \\
\hline
\end{tabular}

Table 4.3 shows the result of the Control Group. It is noted that the majority of the students were able to score well in the Pretest and all of them passed the reading test. Four students managed to get distinctions in the reading test without the implementation of CLT. On the other hand, after implementation of the treatment, all the students showed amazing improvement in the Post-test and all of them managed to pass the reading tests with flying colours compared to the Pre-test result. One of them managed to score full marks in the reading test. This indicated that CLT is an effective approach in teaching ESL reading classrooms.

The significance level (alpha level, $\alpha$ ) is 0.05 . With degree of freedom, $d f=N-1$ (refer to t-table) $11-1=10$, thus the critical value equals \pm 2.23 for $\alpha=0.05$.

$S_{\bar{D}}=\sqrt{\frac{\sum D^{2}-\frac{\sum D^{2}}{N}}{N(N-1)}}$

where $\Sigma D^{2}=$ sum of the squared differences scores

$\Sigma D=$ sum of the difference scores

$N=$ number of pairs

$=\sqrt{\frac{2980-\frac{2980}{11}}{11(10)}}$

$=\sqrt{\frac{2709.09}{110}}$

$=\sqrt{24.63}$

$=4.96$ 
The full formula for $t$ when the samples are dependent is as shown below:

$$
t=\frac{\bar{D}}{\sqrt{\frac{\sum D_{2}-\frac{\left(\sum X\right)_{2}}{N}}{N(N-1)}}}
$$

$$
=\sqrt{\frac{14.18}{4.96}}
$$

$=2.86$

Based on the result above, $t=2.86$ with $d f=N-1$

$11-1=10$. Therefore, the obtained value of $t$ is bigger than the critical values, \pm 2.23 . Thus, the result is insignificant at the 0.05 level. The conclusion is that there is insufficient evidence to conclude statistically that the two sets of tests strongly affect the English reading skills of the ESL secondary homeschooling students in Malaysia.

Moreover, CLT also focuses on and aims at communicative competence. Thus, this allows the learners to use the language in a communicative situation to satisfy their needs in real-life communication which is a priority in CLT (Richards, 2006). In other words, it brings the real life situations of the students into classroom activities such as role-play and simulation.

At this juncture, it could be argued that CLT is an effective instructional approach and has a positive impact on learners' reading performance in secondary homeschooling. As the results are consistent with the findings of other studies in that CLT is an effective strategy, it is advisable that this strategy be incorporated into secondary ESL classrooms.

\subsection{2 : Benefits of CLT in ESL Reading Classrooms}

All the students strongly agreed that they were able to learn more from each other when learning new vocabulary during the reading class as well as improve their pronunciation when they try to communicate with other group members. In terms of reading, they learned more vocabulary through group discussion and improved their reading comprehension skills when they discussed with their group members by sharing their ideas and opinions. Group work stimulated their senses and helped them remember stories as they talked and acted on the words. For ESL learners to benefit from CLT activities, they need to learn to remember new vocabulary by using the dictionary and also by writing down the words and their meanings in a notebook. CLT activities will make this process more interesting and the group will provide the necessary energy for this benefit to materialise.

In the random interview, interviewee 14 described that CLT was very effective and made learning English interesting. During the English reading classes, students usually communicate in English and found it quite useful learning vocabulary. Whenever they found a new word, they would look for the meaning from the dictionary. Interviewee 15 shared that students who were involved in the communicative approach in the group discussion found that they could share their ideas and opinions with each other and therefore tend to learn more.

In addition, interviewees 15 and 16 pointed out that CLT approach is interesting because discussions usually help students to effectively communicate with each other thus increasing their self-confidence. They normally have the courage to present their findings in front of everyone in the class. Not only that, they also from other group members positive attitudes such as selfdiscipline, self-responsibility, self-motivation and self-confidence through the group work. In short, communicative activities are not only more lively and interesting but are more beneficial to all the group participants.

Interviewee 15 pointed out that teachers only teach what they are supposed to in the regular English classrooms. For the more student-centred communicative classroom activities, students however learn more from each other and do research by themselves on topics that they do not understand. These communicative activities are more practical, relevant and realistic thus making the English reading classes more interesting and lively and interactive for everyone to participate. The learning experience gained through involvement in communicative activities is more positive for the second language learner. They also manage to learn aspects of nonverbal communication like eye contact and facial expression from others through this communicative approach. These responses concur with Brown's (2010) when highlighting the four characteristics of CLT below: 
a). A focus on classroom tasks that prepare students with the fundamental and essential skills for communication in contexts outside the classroom.

b). A focus on cultivating independent learners who could continue to learn the language beyond the classroom contexts.

c). A focus on the role of teachers as a facilitator instead of a knowledge provider.

d). A focus on the role of the students as active participants in the classroom where emphasis is highly placed on cooperative and collaborative learning.

However, some students found that some of the group members who were unable to speak well in English were unable to provide constructive feedbacks and tend to look at CLT as playtime. Most of the time, they depended on the good students to do their job for them and they found it hard to communicate with them. Some students pointed out that it was a waste of time to explain the concepts of a particular topic to other students as they would not understand the concepts anyway. One student said,

"We realised that some of the group members who could not speak well in English were unable to provide constructive feedback, and tend to look at CLT as playtime. Sometimes, it is a waste of time to explain the concepts of a particular topic to some students as they are unable to understand the concepts well."

\subsubsection{Classroom Observation}

During classroom observation, a majority of the students encountered problems during English reading classes which included problems with vocabulary and pronunciation, lack of understanding of the assigned passages, unable to read smoothly and unable to communicate well in English. Besides that, some of the students spoke mandarin (their mother tongue) to their group members and friends who sat near them.

Basically, the majority of home-schools students tend to have a positive learning experience in the CLT class as they strongly agree that it helps them to learn many more new words and improve their comprehension of the reading passage through group discussions where they can share and exchange ideas and opinions with other group members.

\subsection{Summary}

Basically, the findings and discussion in this chapter are the key findings of quantitative data collected through the questionnaire (perceptions of students and teachers), Pre-test and Post-test and classroom observation, and qualitative data collected through the structured interview with students and teachers as well as classroom observation. The collected data were recorded, interpreted and analysed to generate major themes which were relevant to the research objectives. Results from classroom observation and structured interview for students contributed to RQ 1. The students and teachers' perceptions of CLT derived from the questionnaire and partially from the structured interview provided responses to RQ 2. Finally, the Pre-test and Post-test were designed to elicit information on the students' reading ability before and after implementation of treatment.

The major qualitative finding refers to home-schools students' positive perception of the application of the communicative approach in the ESL reading classrooms. It is concluded that statistically the two sets of tests strongly affected the English reading skills of the ESL secondary homeschooling students in Malaysia. As for the qualitative data analysis, it can be concluded that the communicative approach plays a significant role in improving the reading skills of the secondary homeschooling students in Malaysia.

\section{Conclusion}

\subsection{Introduction}

Essentially, this chapter begins with the conclusion of the study which put emphasis on the perceptions of the secondary homeschooling students on the use of CLT in their reading classrooms and how does CLT contribute to ESL learners' reading skill. Then, it presents the implications of the study. Finally, the study is concluded with recommendations for future studies and lastly follow by summary of the chapter.

\subsection{Conclusions}

This study was designed with the objectives of quantitatively and qualitatively investigating the perceptions of secondary homeschoolings students on the application of the CLT in their reading classrooms. In addition, it also qualitatively investigated to the effectiveness of CLT approach to ESL learners' reading skill. 


\subsubsection{Learner Reading Performances in Experimental and Control Groups}

The dependent $\mathrm{t}$-test results for the both groups demonstrated an extensive improvement in their score comparing the pre to post-test scores. This indicated that all the learners had improved in the English language proficiency and also stressed that teaching and learning had taken place effectively. The results, imply that there was significant differences in the pre and posttests scores in both cases, Experimental and Control. Thus, we could conclude that the two sets of tests strongly affect the English reading skills among the ESL secondary home- schooling students in Malaysia. Based on the results of this study, it can be noted that the reading skills of the students have improved after implementation of the treatment and majority of them able to achieve better result in the reading tests.

\subsubsection{Perceptions Regarding CLT}

\subsubsection{Learners}

In term of the students' perceptions on CLT, the findings of this research revealed that majority of the learners strongly agreed that CLT is an effective and useful approach in learning English reading in the ESL classrooms whereby they can learn more vocabulary through group discussion and improve their reading comprehension much better when they discuss with their group members through sharing and exchanging of ideas and opinions. Moreover, the total of the students' responses and attitude were very positive and motivated that they strongly agreed with the use of CLT for improving their reading skills as the CLT approach has changed the reading class atmosphere to be better than before. Therefore, the home-schoolings students felt pretty cheerful, comfortable and excited during the learning process of reading using CLT activities. This result strongly support the social cultural theory of Lev Vygotsky (1978) that describes learning as a social process that develops gradually through the integration of social, cultural and biological elements. As highly emphasised by Vygotsky (1978), social interaction plays a foundational role in cognition development. Based on his opinion, students manage to learn on two levels: (i) through their communication with others in an extensive range of activities and (2) by thinking deeply on new strategies and knowledge that have become assimilated into the mental structure of the students (Arumugam, 2013; Cross, 2010).

Basically, both home-schoolings teachers tend to have a clear, positive and supportive attitudes and perceptions toward CLT. They strongly agreed that CLT is an effective and useful teaching method to accommodate the demands of the time as this method put high emphasis on the interpersonal skill, stimulate the students to communicate their enthusiasm as well as stimulate their interest in their learning process. Moreover, this approach is advantageous and favourable as the approach is to involve every student in the communicative activities and places high emphasis on communication which highly encouraged the students to communicate and interact with each other as well as stimulate their interest in English learning and developing their learner autonomy.

\subsubsection{Teachers}

The teachers perceived that CLT was a good way of generating language input and output. This study also indicated that the possibility of implementing the communicative approach in Malaysian ESL context. Teachers exhibited their willingness to include communicative activities in their reading classrooms as they have a positive perception and understanding of the application of the communicative approach. In addition, both teachers in this study were found to be enthusiastic to apply the communicative approach in the ESL reading classrooms. Besides that, the home-schooling students also show a positive attitudes and perceptions on the use of communicative approach in the ESL reading classrooms whereby they strongly agreed that the communicative approach enable them to learn more new vocabulary and improve their reading comprehension as well as reading skills through the communicative activities such as group discussions. This support Halliday theory (1969) that defines language as a system for expressing meaning in context. It is therefore crucial for the students to play with language, practice amongst peers and access the rules of languages in order to improve language skills (Halliday, 1969). In addition, it also supports Haneda and Wells theory (2008) who opined that language is not encountered or learned as an abstract system of decontextualized rules and definitions. Rather, language occurs as a dialogue. Since this covert language teaching cannot be easily depicted in the classroom, learning a second language among children requires diversified opportunities to employ in dialogic interactions in a variety of contexts with the intention of accessing their higher mental functions (Vygotsky, 1978; Wells, 2000).

\subsection{Implications of the Study}

Basically, this research conducted to investigate the perceptions of secondary home-schooling students on the application of $\mathrm{CLT}$ in their reading classrooms. The CLT approach has played a significant role in ELT in various developing countries such as Malaysia which is a multicultural society with three major ethnics, i.e. Malay, Chinese and Indian students. In such a condition, teachers should pay attention to students' cultures and their first language. Based on the findings, it can be concluded that communicative approach is effective in teaching reading skills in Malaysian secondary home-schooling ESL classrooms. As 
explained in the discussion, both teachers and the students agreed that CLT is beneficial and advantageous for their pedagogical reading purposes and most of the respondents strongly believed that this approach should be more suitable to the Malaysia ESL context. As compared to the traditional method such as Grammar Translation Method, communicative approach would be highly favourable and more applicable in the Malaysian secondary home-schoolings.

Optimistically, the findings of the current research are advantageous and beneficial for many people who can benefit from these current research findings. Firstly, the executive administrators in the Ministry of Education of Malaysia, who can apply the findings of the current study to improve and revise the current curriculum to the Malaysian secondary home-schooling in the advantageous and favourable way for the pedagogical reading of the students. Secondly, textbook authors who can apply these findings to revise reading materials based on the requirements of the learners and teachers so that they can design and adopt reading textbooks according to the needs of the learners and teachers. In the same time, they can apply this research findings to improve Malaysian secondary schools reading textbooks. Finally, the students who can express their viewpoints and opinions concerning CLT and its implementation in Malaysia.

\subsection{Recommendations for Future Studies}

Since this study focus on the ESL secondary home-schooling students, the future studies could be implemented by interviewing the secondary students from both government schools and international schools in order to study and compare their attitude, viewpoints and perceptions on the application of communicative approach in English Language Teaching. In addition, the future studies can be conducted which focus on both ESL and EFL contexts since this study only emphasized on ESL context.

Funding: This research received no external funding.

Acknowledgments: First and foremost, I would like to take this opportunity to express my deepest gratitude and appreciation to my family members and friends who provide spiritual and emotional support to me in encouraging and motivating me to successfully complete my thesis. During my studies, I encountered various obstacles and difficulties which made me believe that I unable to submit my thesis on time and may require to extend the date of my thesis submission. Fortunately, family members and friends were always there to provide the necessary assistance and inspiration so that I could complete my thesis successfully. Thanks for the continuous encouragement and motivation. A special gratitude is dedicated to my supervisor, Associate Professor Dr Nalini Arumugam for the boundless effort in conveying knowledge and information to me since the beginning of this study. Her help and support, tolerance as well as her valuable and useful feedback are highly appreciated. With her continuous assistance and beneficial guidance, I have managed to complete my thesis on time. Thanks again for the tireless effort in guiding me to the end.

Conflicts of Interest: The authors declare no conflict of interest.

\section{References}

[1] Alexander, T. (2016). An Introduction to Qualitative and Quantitative Methods. Second Term, General Sociology 2. Department of Sociology, Rhodes University.

[2] Assefa, T. (2012). Teachers' and Students; Perception of Communicative Language Teaching [M.A Thesis], Addis Ababa: Addis Ababa University.

[3] Bagaric, V. (2007). Defining Communicative Competence. Faculty of Philosophy, University of Osijek.

[4] Bean, T.W., Readence, J.E., \&amp; Baldwin, R.S. (2011). Collaborative Strategic Reading (CSR) : An integrated approach, (10th ed.).

[5] Belchamber, R. (2007). The advantages of communicative language teaching. The internet TESL journal, 13(2), $122-149$.

[6] Bilash, O. (2011). Foreign Language (FL) vs. Second Language (SL) Context. Department of Secondary Education, University of Alberta, Canada.

[7] Broadhurst, D. (1999). Investigating young children's perceptions of home-schooling. Paper presented at the Australian Association for Research in Education, Melbourne, Australia.

[8] Brown,H.D. (2010). Principles of Language Learning and Teaching. 6 th ed. Englewood Cliffs, NJ: Prentice-Hall.

[9] Bryman, A. (2008). Social Research Methods (3 rd ed.). Oxford: Oxford University Press.

[10] Bryman, A. (2012). Social Research Methods (4 th ed.). Oxford: Oxford University Press.

[11] Burns, R. (1997). Introduction to Research Methods (3 rd ed.). Melbourne: Longman.

[12] Celce, M. (2009). Communicative Language Teaching. An Overview. New York: Plenum Press, pp. 50-87.

[13] Chan, S. H. \&amp; Tan, H. (2006). English for Mathematics and Science: Current Malaysian Language- in-education Policies and Practices. Language and Education, 20(4), 306-322.

[14] Chang, M. (2011). EFL Teachers' Perceptions toward Communicative Language Teaching in Taiwanese College. Asian EFL Journal Professional Teaching Articles, 53, 17-34.

[15] Chung, S. F. (2017). A communicative approach to teaching grammar: theory and practice. The English Teacher, 18.

[16] Cohen, L., Manion, L. \&amp; Morrison, K. (2007). Research Methods in Education (6 th ed.). Abingdon: Routledge.

[17] Cohen, L., Manion, L. \&amp; Morrison, K. (2011). Research Methods in Education (7 th ed.). Abingdon: Routledge.

[18] Ellis, G. (1996). How culturally appropriate is the communicative approach?. ELT journal, 50(3), 213-218. 
[19] Darmil, R. \&amp; Albion, P. (2013). English Language in The Malaysian Education System : Its Existence and Implications. Faculty of Business, Education, Law and Arts, University of Southern Queensland (USQ), Australia \&amp; Center for the Advancement of Language Competence, Universiti Putra Malaysia (UPM), Malaysia.

[20] Davidson, C. \&amp; Tolich, M. (2003). Making Sense of the Data. In C. Davidson, \&amp; M. Tolich (Eds.), Social Science Research in New Zealand: Many Paths to Understanding (2 nd ed.)(pp. 154- 175). Auckland: Pearson Prentice Hall.

[21] Davidson, C. \&amp; Tolich, M. (2003). Collecting the Data. In C. Davidson, \&amp; M. Tolich (Eds.), Social Science Research in New Zealand: Many Paths to Understanding (2 nd ed.)(pp. 121-153). Auckland: Pearson Prentice Hall.

[22] DeWalt, K. \&amp; Dewalt, B. (2002). Classrooms Observation: A Guide for Fieldworkers. Walnut Creek, CA: AltaMira Press.

[23] Elmusharaf, K (2012). Qualitative Data Collection Technique. Newbury Park, CA: Sage.

[24] Goodmacher, G \&amp; Kajiura, A. (2010). Communicative Reading. New York: McGraw-Hill, Inc., pp. 44-58.

[25] Halliday, M. (1969). Relevant Models of Language. Educational Review, 21(3), 26-37.

[26] Halliday, M. (1975). Learning How to Mean: Explorations in the Development of Language.London, UK: Edward Arnold.

[27] Harmer, J. (2001). The Practice of English Language Teaching (2 nd ed.). London: Longman.

[28] Haneda, M. \&amp; Wells, G. (2008). Learning An Additional Language through Dialogic Inquiry. Language and Education, 22(2), 114-136.

[29] Henrichsen, P. (2007). Perceptions of Chinese Teacher toward Western Language Teaching. New York, Pergamon Press.

[30] Hinds, D. (2000). Research Instruments. In D. Wilkinson (Ed.), The Researcher's Toolkit: The Complete Guide to Practitioner Research. (pp. 4145). London: Routledge.

[31] Inderjit, S. (2014). Reading Trends and Improving Reading Skills Among Students in Malaysia. Faculty of Defense Studies and Management, National Defence University Malaysia.

[32] Kamhuber, P. (2010). Approaches and Methods in Language Teaching. Sydney: National Centre for English Teaching and Research.

[33] Kasim, S. (2015). Teachers' Perceptions on Communicative Language Teaching. Faculty of Education, University Teknologi Mara.

[34] Krueger, R. A. \&amp; Casey, A. (2000).Focus Groups: A Practical Guide for Applied Research (3 rd ed.).Thousand Oaks: Sage.

[35] Kunzman, R. \&amp; Gaither, M. (2013). Homeschooling: A Comprehensive Survey on the English Language Teaching. The Journal of Educational Alternatives, 2(1), 4-59.

[36] Larsen-Freeman, D. (Ed.). (2000). Techniques and Principles in Language Teaching (2 nd ed.). Oxford: Oxford University Press.

[37] Leedy, P. D. \&amp; Ormrod, J. E. (2013). Practical Research Planning and Design (10 th ed.). New Jersey: Pearson Education.

[38] Leipzig, D.H. (2001). What is Reading? WETA. http://www.readingrockets.org/article/what-reading.

[39] Liao, X. Q. (2000). Communicative Language Teaching Innovation in China: Difficulties and Solutions. Retrieved from ERIC database (ED 443294).

[40] Linderholm, T. \&amp; Broek, P. (2002). The Effects of Reading Purpose. Journal of Educational Psychology, 778-784.

[41] Littlewood, W. (2007). Communicative Language Teaching in Asian Classrooms. Language Teaching, 40, 243-249.

[42] Mahbub, A. (2008). The CLT Approach in ELT: Its Effectiveness in the ESL and EFL Contexts. ManaratInternational University Studies (Journal of Manarat International University), 1(1),131-142.

[43] Marshall, A. \&amp; Rossman, T. (2005). Designing Qualitative Research (2 nd Edition). Newbury Park: Sage.

[44] Motteram, G.(2013). English Language Teaching. British Council, UK.

[45] Newby, P. (2010). Research Methods for Education. Edinburgh Gate: Pearson Education.

[46] Nordquist, R. (2015). English as a Second Language (ESL) Definition. About.comhttp://grammar.about.com/od/e/g/English-As-A-SecondLanguage-Esl.html.

[47] Norlidah, A., Mohd, N., Saedah, S., Ruslina, I. (2012). A Model of Homeschooling Based on Technology in Malaysia. The Malaysia Online Journal of Educational Technology, 1(3).

[48] Novita, D. (2012). The Effectiveness of Collaborative Strategic Reading for Teaching Reading Comprehension. Muhammadiyah University of Sidoarjo.

[49] Nunan, D. (2003). The Impact of English as a Global Language on Educational Policies and Practices in the Asian-Pacific Region. TESOL Quarterly, 37(4), 589-613. Pacek, D. (1996).

[50] Ozsevik, Z. (2010). The Use of Communicative Langauge Teaching (CLT): Turkish EFL Teachers' Perceptions in Implementating CLT in Turkey. University of Illinois at Urbana-Champaign

[51] Paulista, S. \&amp; Gomez. (2014). The Application of Communicative Language Teaching. Faculty of Education, University of Victoria.

[52] Radzi, M., Azmin, A.H., Zolhani, A.M., \&amp; Latif, S.A (2007). Adopting Communicative Language Teaching (CLT) Approach to Enhance Oral Competencies Among Students: Teachers' Attitudes and Beliefs. Faculty of Communication and Modern Languages, Universiti Utara Malaysia.

[53] Ray, B. D. (2013). Homeschooling associated with beneficial learner and societal outcomes but educators do not promote it. Peabody Journal of Education, 88(3), 324-341

[54] Rhalmi, M. (2009). Communicative Language Teaching (The Communicative Approach). http://www.myenglishpages.com/blog/communicative-language-teaching-communicave-approach

[55] Richards, J.C. (2006). The Communicative Language Teaching Todays. Cambridge University Press.

[56] Richards, J. \&amp; Rogers, T. (2014). Approaches and Methods in Language Teaching. Cambridge: Cambridge University Press.

[57] Richards, J. \&amp; Rogers, T. (2001). Approaches and Methods in Language Teaching. Cambridge: Cambridge University Press.

[58] Sarab, M.A., Monfared, A. \&amp; Safarzadeh, M.M. (2016). Secondary EFL School Teachers' Perceptions of CLT Principles and Practices. Urmia University Press.

[59] Saunders, M., Lewis, P. \&amp; Thornhill, A. (2009). Research Methods for Education (5 th ed.). New York: Prentice Hill.

[60] Savignon, S. J. \&amp; Wang, C. (2003). Communicative Language Teaching in EFL context: Learner Attitudes and Perceptions. IRAL, 41, 223249. 
[61] Sekaran, U. \&amp; Bougie, R. (2010). Research Methods for Education: A Skill Building Approach (5 th ed.). New Jersey: John Wiley \&amp; Sons.

[62] Smyth, R. (2009). Introduction to Research Methods in Education. John Wiley \&amp; Sons, Inc.

[63] Stokes, D. \&amp; Bergin, R. (2006). Methodology : An Evaluation of Focus Groups and In-depth Interview. Qualitative Market Research: An international Journal, 9(1), 26-37.

[64] Thamarana, S. (2015). A Critical Overview of Communicative Language Teaching. Andhra University, India.

[65] Vygotsky, L. S. (1978). Mind in Society: The Development of Higher Psychological Processes. Cambridge, MA:Harvard University Press.

[66] Wells, G. (2000). Dialogic Inquiry in Education: Building on the Legacy of Vygotsky. In C. D.Lee \&amp; P. Smagorinsky (Eds.), Vygotskian Perspectives on Literacy Research. New York: Cambridge University Press.

[67] Wells, G. (2007). The Mediating Role of Discoursing in Activity. Mind, Culture, and Activity, 14(3), 160-177. Wilson, S. (2005). Homeschool Definition. http://whatis.techtarget.com/definition/home-school.

[68] Wright, T. (2000). Communicative Language Teaching. Can it work for us? In EELTNET. Addis Ababa: British Council.

[69] Ying, L. (2010). Communicative Activities in ELT Classrooms in China. [Unpublished master dissertation]. University of Wisconsin-Platteville.

[70] Yu, L. (2001). Communicative Language Teaching in China: Progress and Resistance. TESOL Quarterly, 35(1), 194-17 